KLEINE TEXTE FÜR THEOLOGISCHE UND PHILOLOGISCHE VORLESUNGEN UND ÜBUNGEN

HERAUSGEGEBEN VON HANS LIETZMANN

59

\title{
DER MIŠNATRAKTAT BERAKHOTH
}

IN VOKALISIERTEM TEXT

MIT SPRACHLICHEN UND SACHLICHEN BEMERKUNGEN

VON

PROF. D. DR. W. STAERK

B O N N

A. MARCUS UND E. WEBER'S VERLAG 
Dem nachfolgenden texte liegt der von $L$. Goldschmidt;

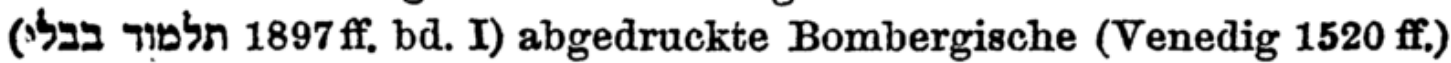
zugrunde. Hier und da ist eine lesart der Münchener handschriften bevorzugt. Für den hauptzweck dieser ausgabe, die erste einführung in das studium der mišna, deren lektüre im urtext sich wenigstens auf die religionsgeschichtlich wichtigsten traktate erstrecken sollte, kann das genügen. Zur erleichterung für die anfänger ist der text jedes paragraphen in sinnabschnitte zerlegt und hier und da durch interpunktion nachgeholfen.

Die ausgabe ist so eingerichtet, daß sie lexikalisch mit hülfe des Gesenius-Buhl'schen wörterbuchs bewältigt werden kann.

Zur ergänzung dient heft 58 dieser sammlung, wo die hier erwähnten liturgischen gebete zusammengestellt sind. Literatur: Strack, einleitung i. d. talmud Leipzig, Hinrichs, 1908 , unentbehrliches hülfsmittel. Schürer, geschichte des jüdischen volkes II, 11907 ebenda. Bousset, religion des judentums 2 1906, Berlin, Reuther u. Reichardt. Fiebig; ausgewählte mišnatraktate - in deutscher übersetzung III. Tübingen, Mohr 1906. Thosephta, ed. Zuckermandel u. dazu L aible, der tosefta-traktat Berakhoth, Rotenburg 1902.

I, 1 a

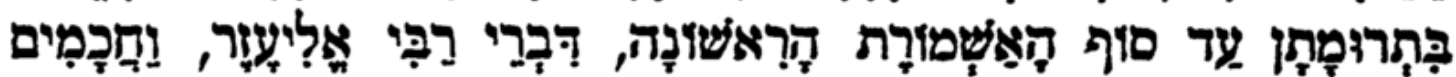

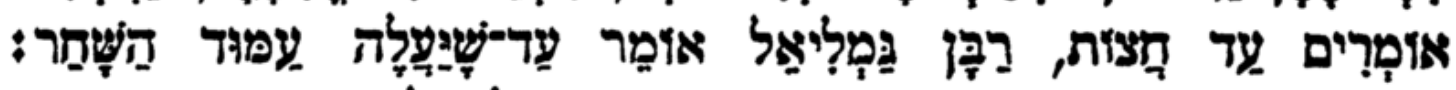

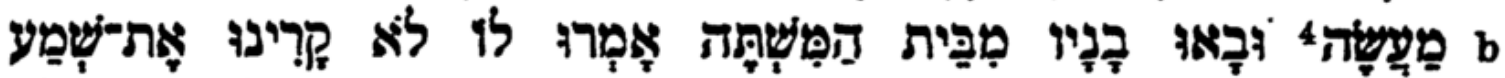

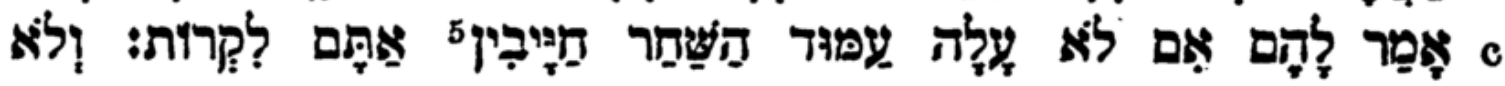

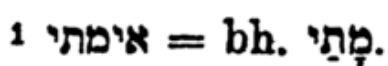

2 קרו 2 ist term. techn. für das šemá, es wird nicht gesprochen; sondern mit eigenartig

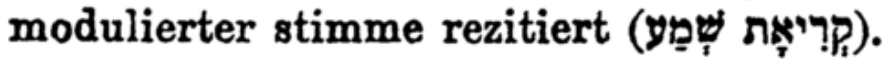
4 factum (est), quod. 4 vgl. bh. חוב; verpflichtet.

I, 1-III, 6: Die kasuistik des šemá. I, 1. Über die zeit des abendgebets. - a) über das še $\mathrm{ma}^{\mathrm{c}} \mathrm{d}$. h. das aus Deut. $6,4-9 ; 11,13-21$ u. Num. 15, 37-41 kombinierte zentrale gebet des judentums, vgl. Schürer a. a. $0.528 f$. u. $537 f$.; die 3 abschnitte 


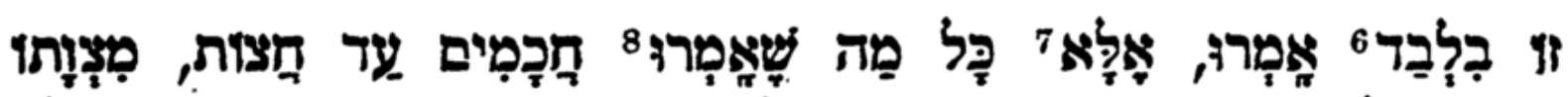

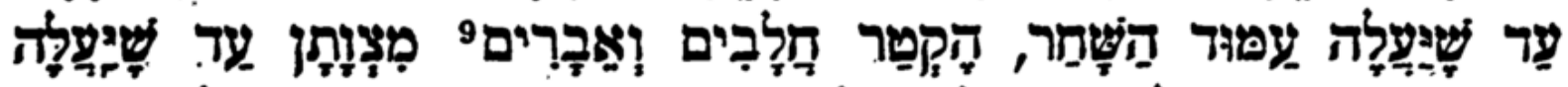

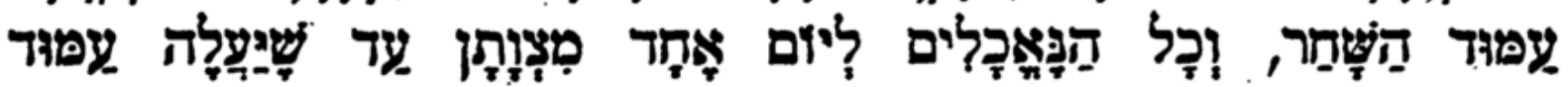

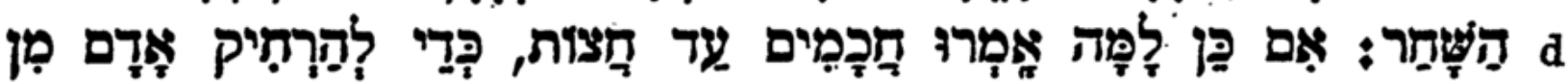

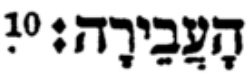

2 a

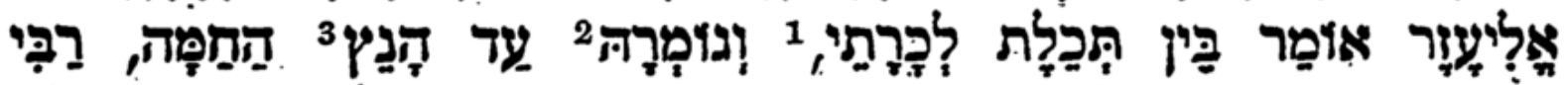

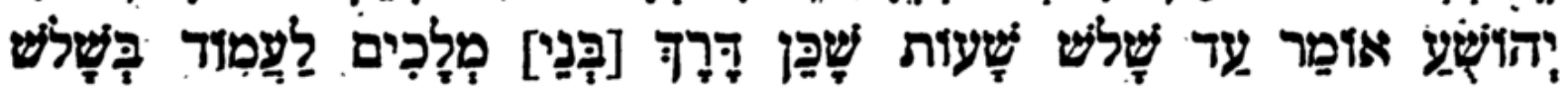

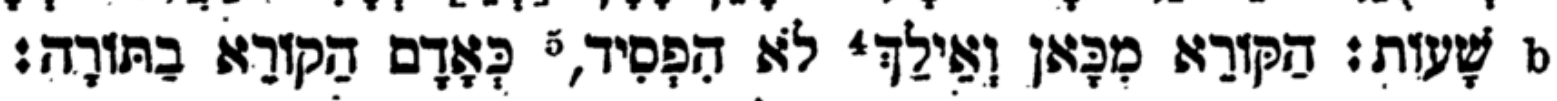

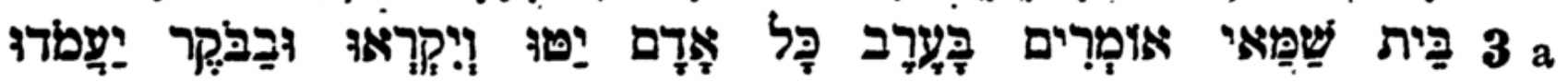

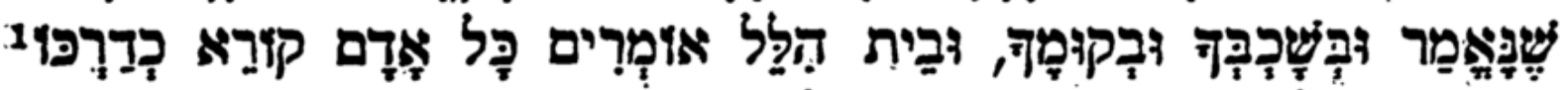
b

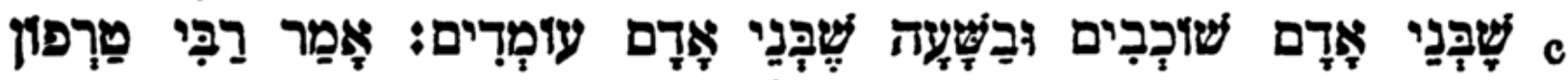

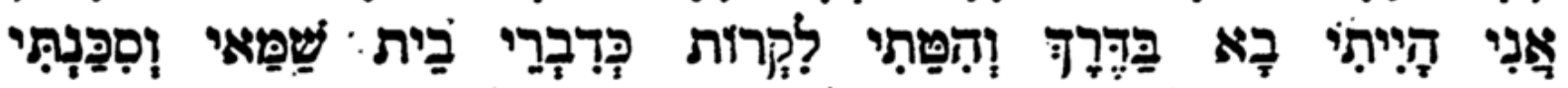

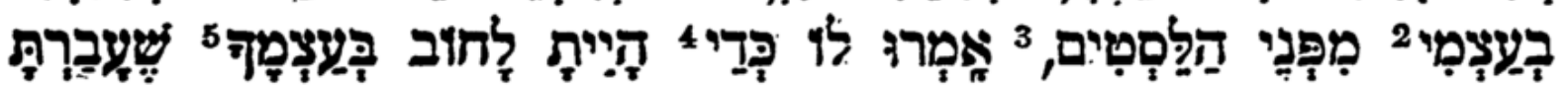

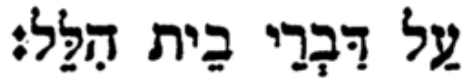

6 non solum hoc. 7 sondern. 8 de quibuscunque dixerunt. $\quad{ }^{9}$ glieder, stücke. $\quad 10$ übertretung $=\tilde{\alpha} \mu \alpha \rho \tau i \alpha$.

2. ${ }^{1}$ lauch(farben); var. bb. $ү$ ss. 4 von da an und weiter. 5 schaden haben.

3. 1 auf seine art. 2 mich (selbst); bh. in dieser bedeutung nur in bezug auf sachen. $3 \lambda \eta \sigma \tau \eta_{\text {s. }}$ " würdig, wert. s dich selbst zu beschuldigen.

des gebetes werden nach ihren anfängen רמֵ genannt. - Zur zeitbestimmung vgl. Lev. 22, 4-7; Num. 18, 8. Die 1. nachtwache (nach talmudischer ordnung) reicht bis etwa 10 uhr. - Die weisen sind die sog. mišna. אמרו wie oben in a. c) das subjekt von Lev. 6, 1-6. - Lev. 7, 15 u. 22, 29 f.

2. Über die zeit des morgengebets. - a) die farben

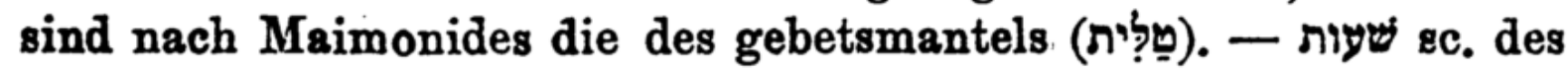
neuen tages, also etwa bis $9 \mathrm{uhr}$.

3. Wie man sich beim šema zu halten hat. - a) ציק sc. das šema'. iv wird bedeuten: in lehnender haltung, nicht: liegend. - Deut. 6, 7. - Der unterschied beider schulen in der schriftauslegung tritt hier deutlich hervor. Schammai's exegese ist echt rabbinisch. 


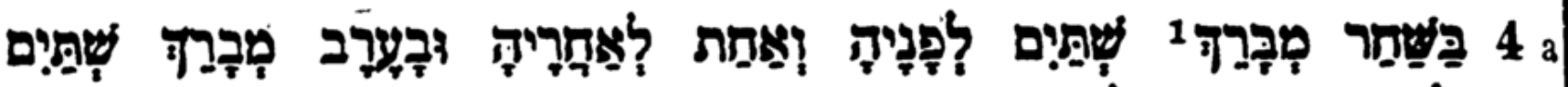

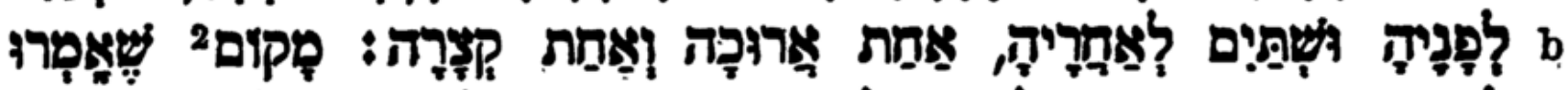

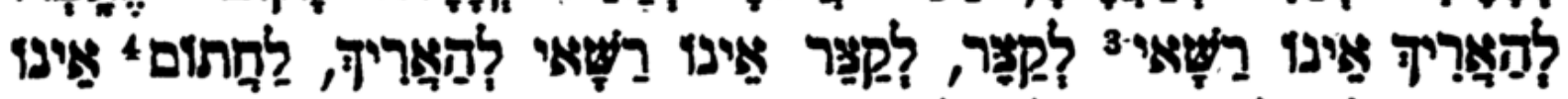

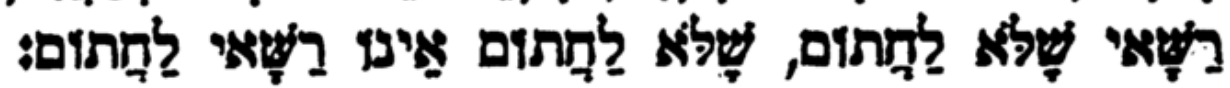

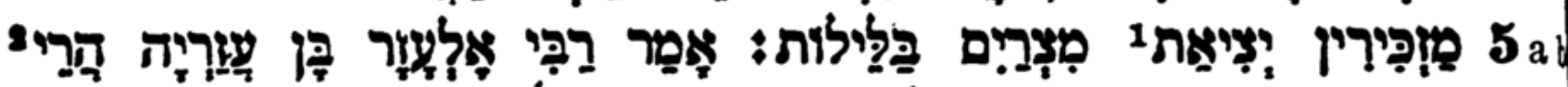

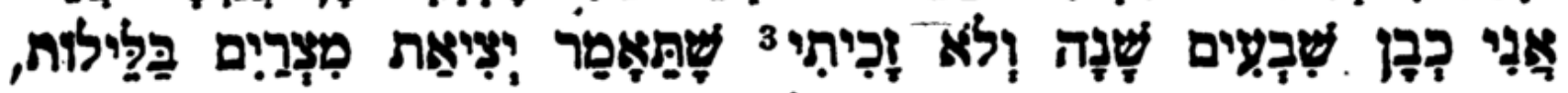

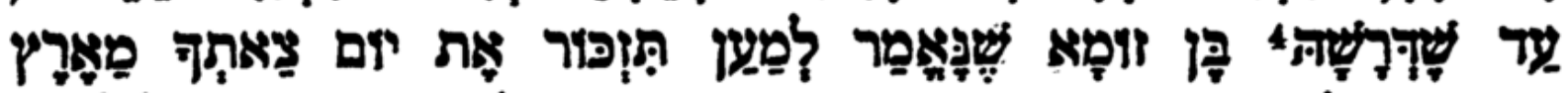

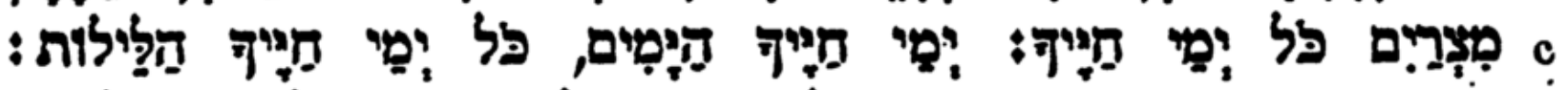
d

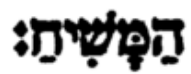

2 II,1.

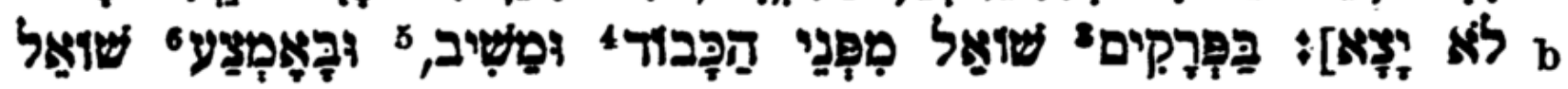

4. 1 eine פָּרָ sprechen. bedeutung: da wo.

2 מקום hier in ganz allgemeiner 3 8. bh. רשו adjektiv nach der form

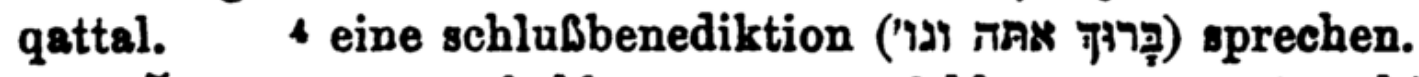

5. 1 auszug, vgl. bh. x'י;

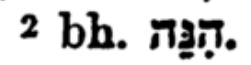

3 recht haben

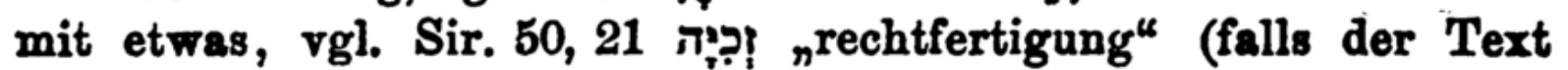
richtig). 4 aus der schrift erforschen. 5 einschließen.

II, 1. 1 frei ausgehen $=$ der pflicht ledig sein. xל. 3 abschnitte (des šemsi, s. u. § 2).

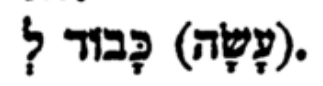
s sc. atל ngrubu, rgl. c) am ende.

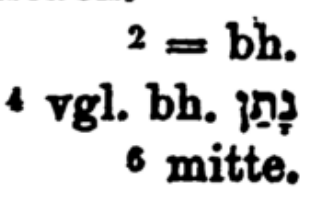

4. Über die benediktionen zum $\check{s}^{\mathrm{e}} \mathrm{mac}$, vgl. heft 58 , 8. $3 \mathrm{ff}$ - - a) die suffixe der praepositionen beziehen sich auf das

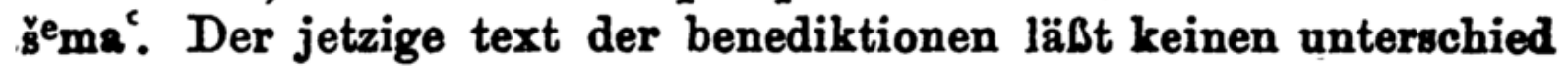
$z$ wischen längeren und kürzeren sprüchen zu, es ist also nicht ganz klar, worauf sich die ausdrücke "länger" und "kürzer" beziehen. Nach der Tosephta Berakhoth $\S 6$ gehörte zu den benediktionen,

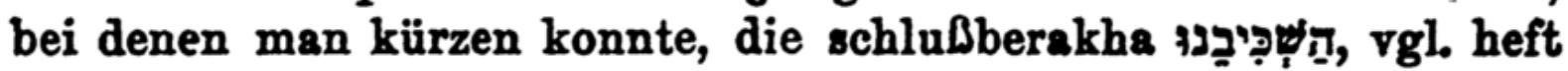
58, s. 9. 'Die texte der benediktionen müssen $z$. zt. der mišna noch flübig gewesen sein.

5. Warum der 3. abschnitt des sema auch abends gebetet wird. - a) 'יצ' ist bezeichnung des 3. teils des šemse (s. 0. § 1) nach dem inhalt von v.41; er heißt auch nיצִ nach dem hauptinhalt. Dieser abschnitt wurde also früher einmal beim abendgebet nicht gesprochen. Den schriftbeweis dafür, daß er auch des abends gebetet werden muß, hat Ben Zoma gebracht.

b) Deut. 16, 3. 


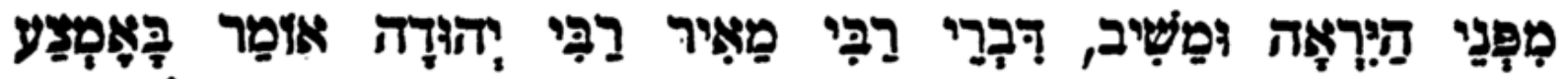

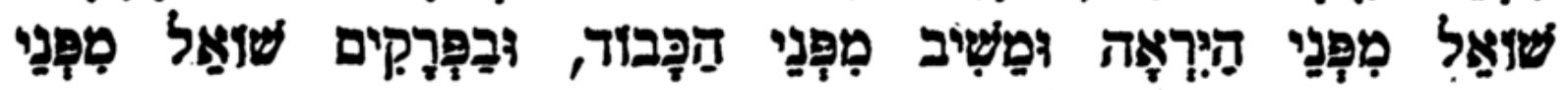

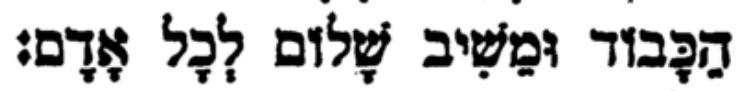

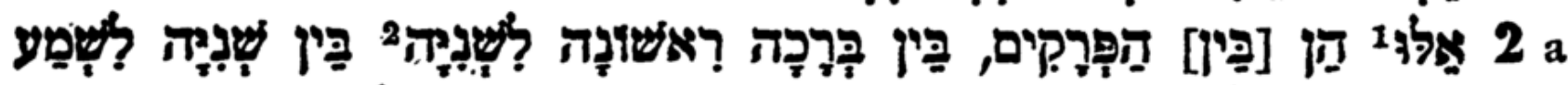

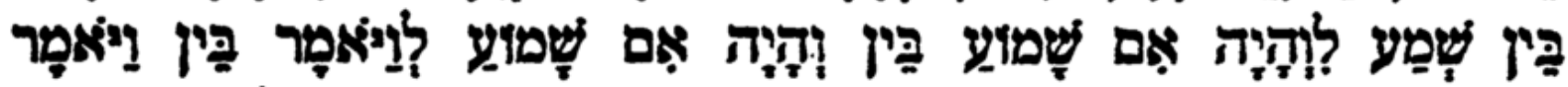

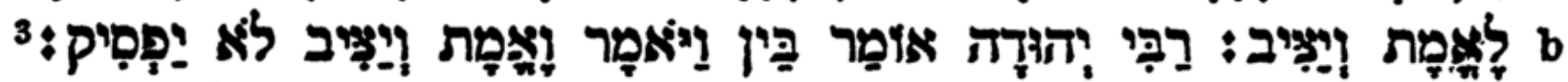

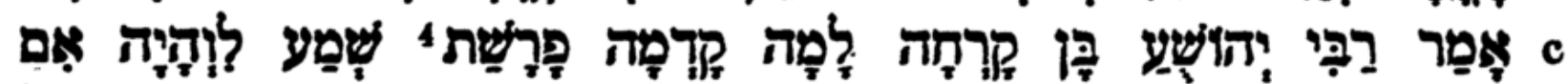

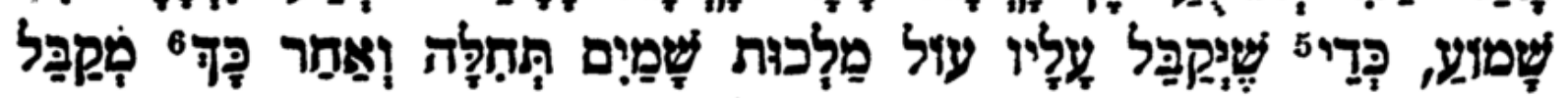

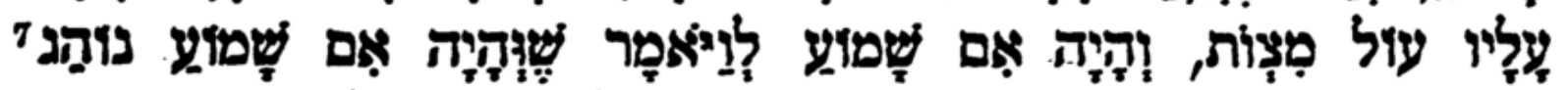

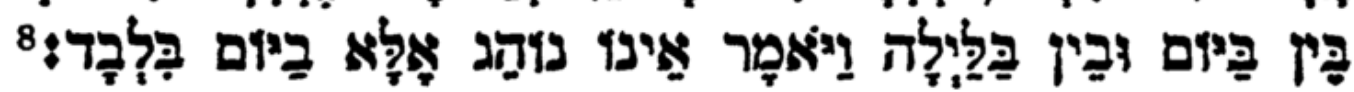

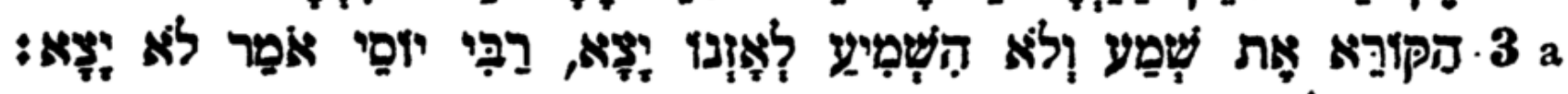

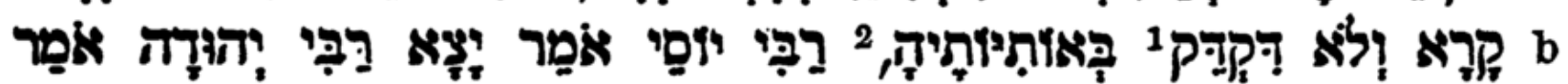

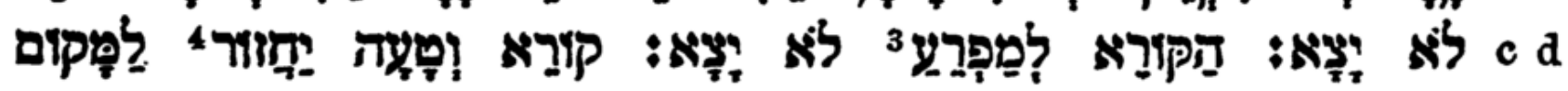
4 :

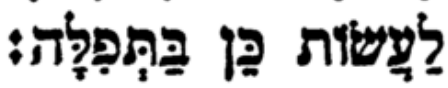

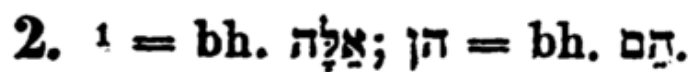

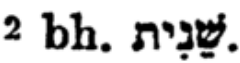
3 einen
4 perikope.
5 vgl. I, 1 d.
6 danach.

abschnitt machen. 7 übt man. 8 nur.

3. 1 genau aussprechen. 2 buchstaben.

3 rückwärts d. h. wohl hier in der umgekehrten ordnung der abschnitte. 4 umkehren.

4. ${ }^{1} \mathrm{vgl}$. bh. 2 gerüst, mauer.

II, 1. Vom lesen des $\mathrm{s}^{e} m a^{c}$ in der thora zurzeit des gebets. Vom grüßen beim gebet. - a) (מרור sc. das šemá. לפין sc. auf die pflicht des šema'lesens.

2. Die abschnitte des šema und ihre reihenfolge, vgl. heft 58, s. $3 \mathrm{ff} .-\mathrm{c}$ ) die reihenfolge der beiden ersten perikopen hätte eigentlich umgekehrt sein sollen, weil $\mathrm{Dt}$. $11,13 \mathrm{ff}$. sich auf alle, Deut. 6, 4 ff. nur auf die einzelnen bezieht, aber der inhalt entscheidet. Das עצול bezieht sich auf Dt. 5, 19; den inhalt des 3. abschnitts kann man eigentlich nur bei tage erfüllen.

3. Wie das še $\mathrm{ma}^{c} \mathrm{zu}$ rezitieren ist.

4. Wo ein arbeiter das še $\mathrm{ma}^{\prime}$ rezitieren darf. - Das ngebet" im gegensatz zum šema ${ }^{\text {e }}$ ist das sog. achtzehngebet, vgl. heft 58, s. $9 \mathrm{ff}$. 


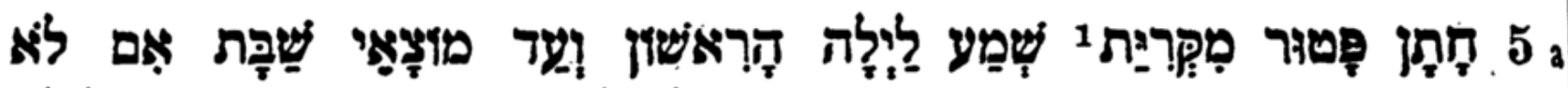

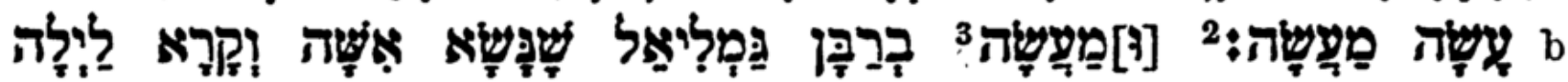

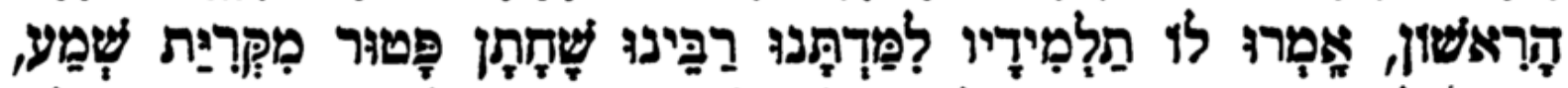

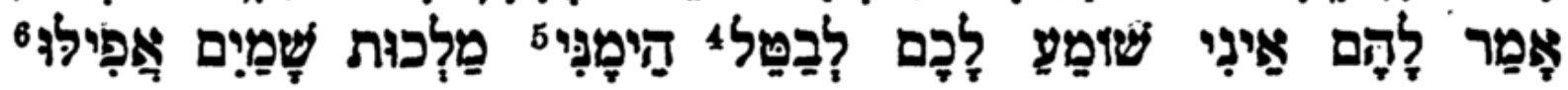

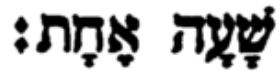

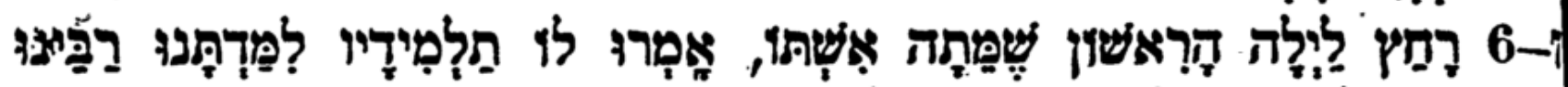

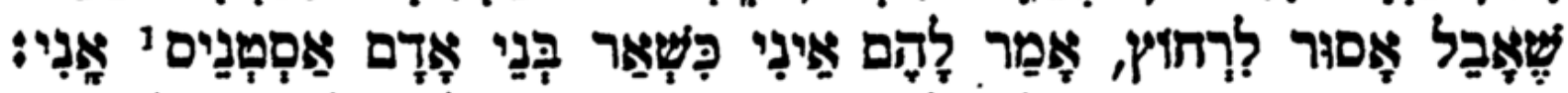

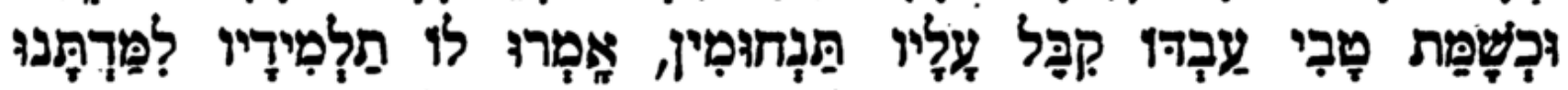

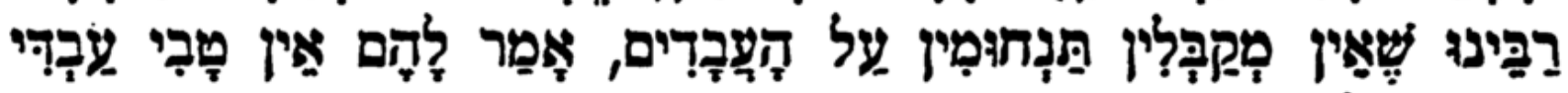

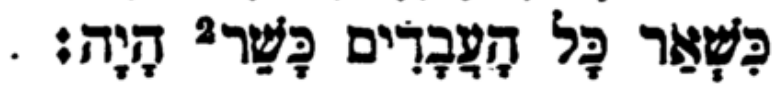

8

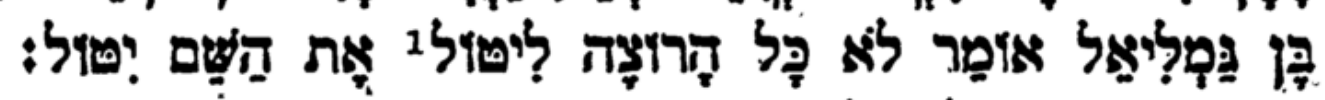
III,

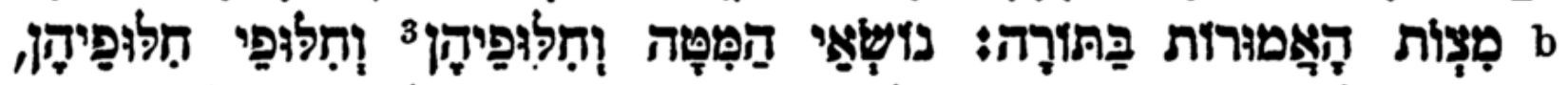

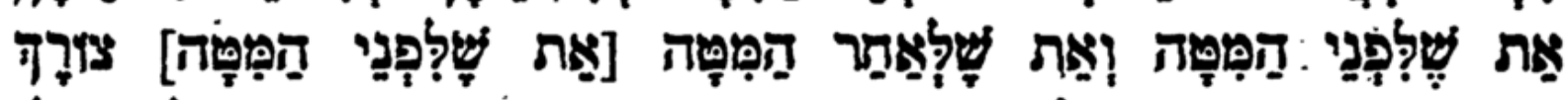

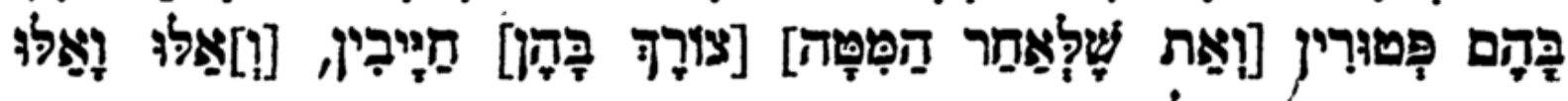

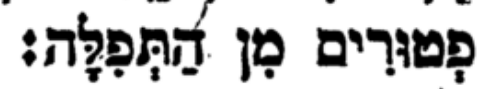
5. 1 = תִיז, vgl. o. I, 1.
2 euphemismus.
${ }^{3} \mathrm{vg}$.
I, 1 c.
4 ablegen.
6-7. ${ }^{1} \dot{\alpha} \sigma \vartheta \varepsilon \nu \eta^{\prime}$.
2 fromm.
$5=$ bh.
6 auch nur.
8. 1 erwerben.

III, $.1-2 .{ }^{1}$ gelegt = liegend. 2 oder 2 ạן Die handschriften schwanken hier. 'ת sind die nt. $\varphi v \lambda \alpha x x \tau_{\eta}^{\prime} \rho \iota \alpha$, die beim morgengebet getragenen kapseln mit den abschnitten Ex. 13,1-10. 11-16; Dt. 6, 4-9; 11, 13-21, vgl. darüber Schürer + II, s. 567 ff.

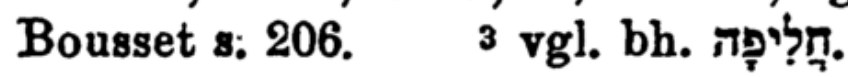

5. Vom rezitieren des še mà in der hochzeitsnacht.a) also bis zum ende der woche, vgl. Tos. Ber. § 10. - In der sab-

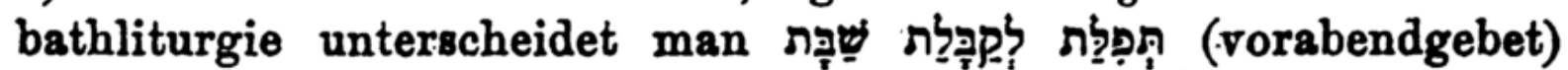
und (gebetordnung am ende des sabbaths) von der

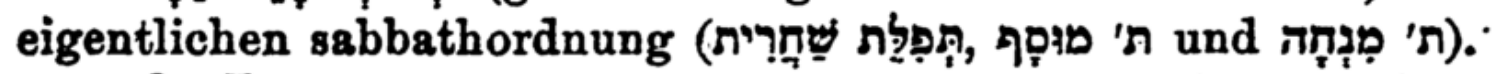

6-7. 1. einschub: zwei weitere beispiele von Rabban Gamliels eigenart.

8. (fortsetzung von §5).

III, 1-2. Vom rezitieren des še $\mathrm{ma}^{c}$ bei einem todesfall und beim begräbnif. - 1. a) der grund ist wie in II, o der 


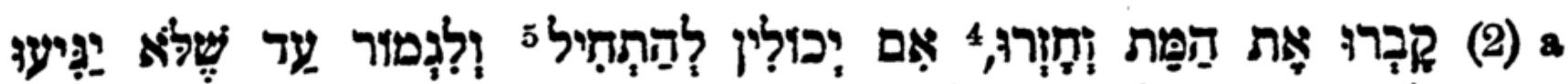

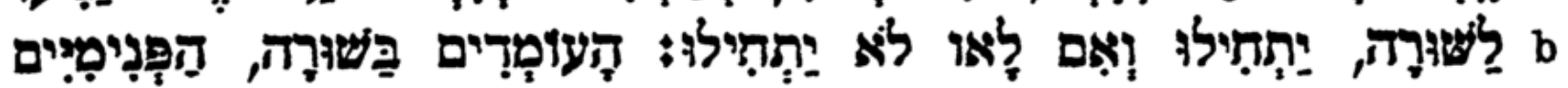

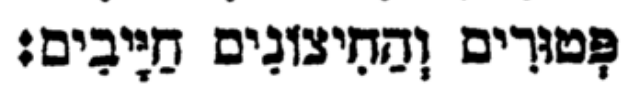

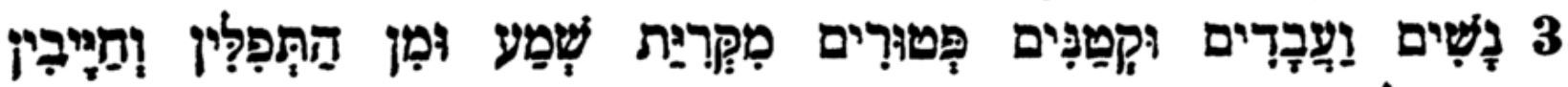

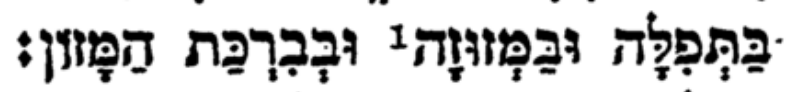

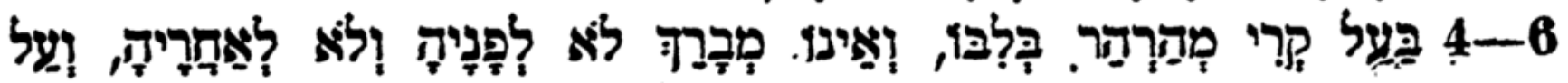

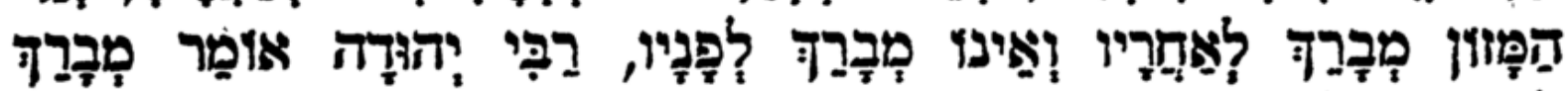

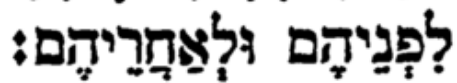

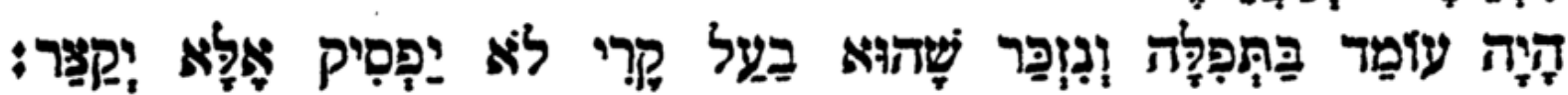
(5) $a$

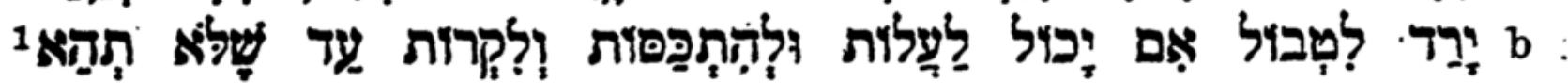

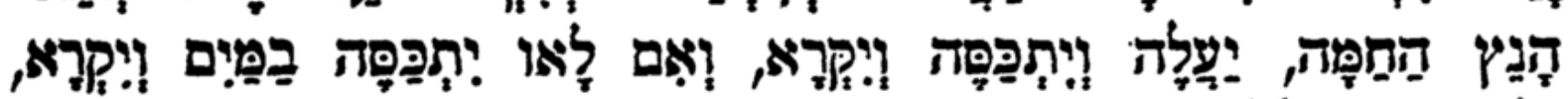

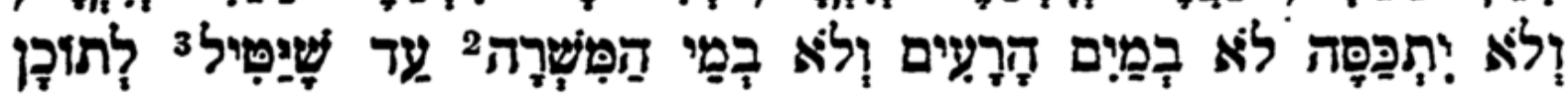

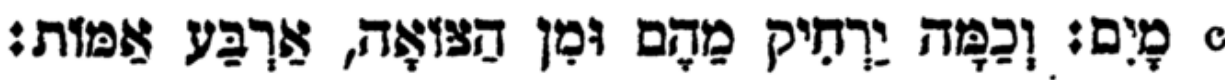

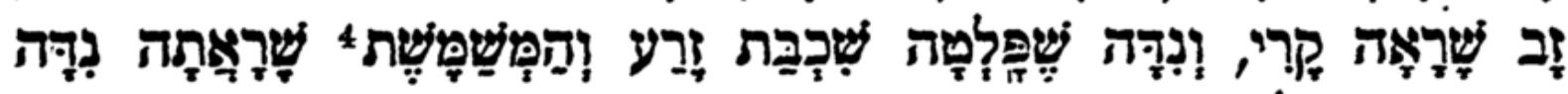

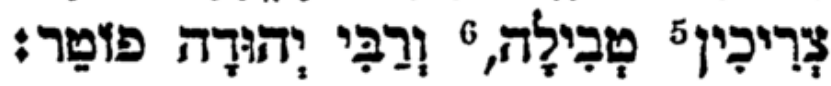

4 zurückkommen. 3 verb. denom. von

3. 1 Die מุist die an den oberen rechten pfosten der eingangstüren befestigte kapsel mit einem pergamentstreifen, der die ersten beiden abschnitte des šemac enthält, vgl. Deut. 6, 9.

4-6. 1 vgl. bh הוה (II). 2 einweichwasser. 3 gießen. - quae concubuit; שמש III eigentlich dienst tun. 5 vgl. III, 1 b. 6 reinigungsbad.

seelische zustand des betreffenden.

1. b) zur ersten gedankenreihe ist das prädikat aus a) zu ergänzen. Im folgenden ist der text nicht in ordnung: das eingeklammerte ist wohl $\mathrm{zu}$ streichen und

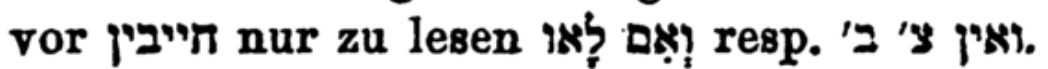

2. a) die שּุ sind die leidtragenden, die nach der rückkehr vom grabe spalier

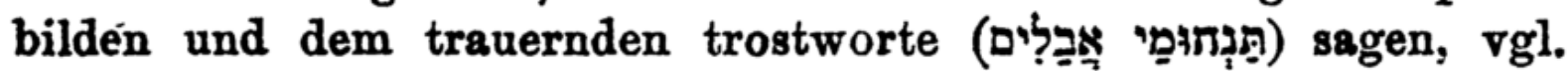
Ber. II, 7 und dazu fol. 16b, Kethubhoth 8, a. Gewöhnlich bilden 10 menschen eine ${ }_{n}$ reihe".

3. Gebetsvorschriften für weiber, sklaven und kinder, vgl. VII, 2. - Der grund für die befreiung ist nach Kiddưšin 29,1 der, daß die genannten gebetsübungen auf eine bestimmte zeit beschränkt sind.

4-6. Wie man sich bei unreinheit durch pollution zu verhalten hat (4-5). Dazu ist 6 eine ad rocem sexuelle 
IV,

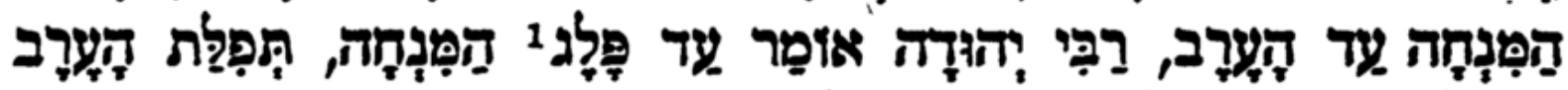

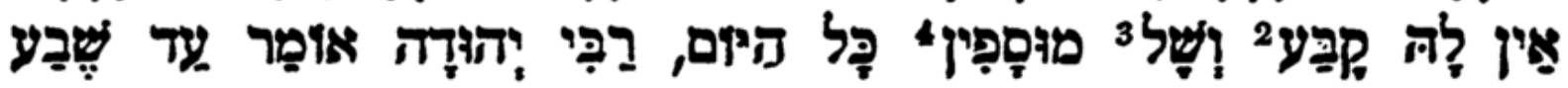

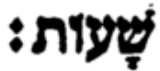

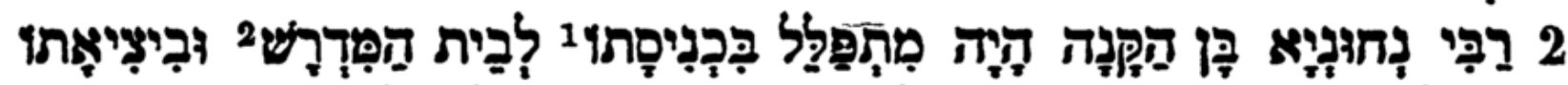

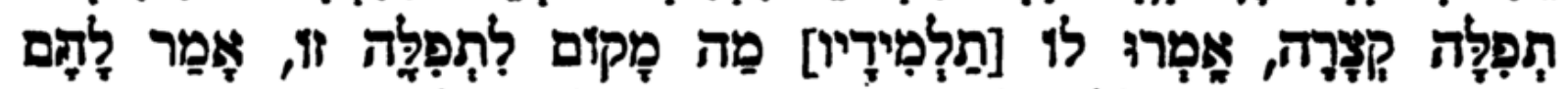

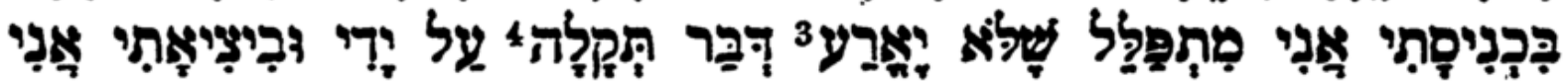

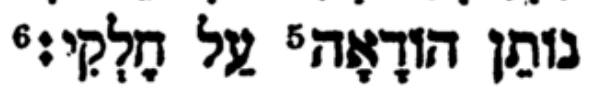

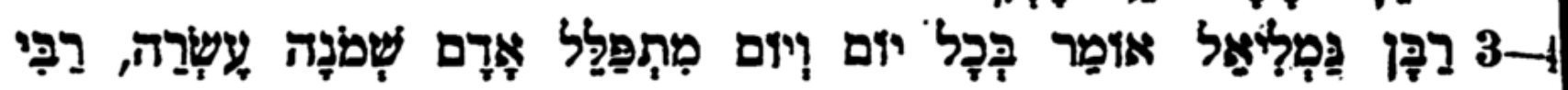

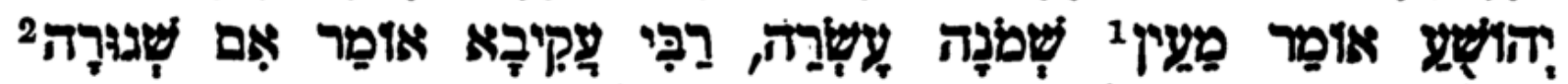

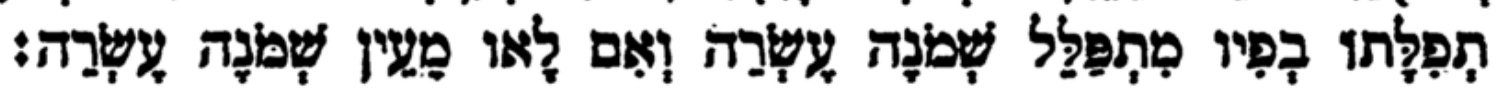

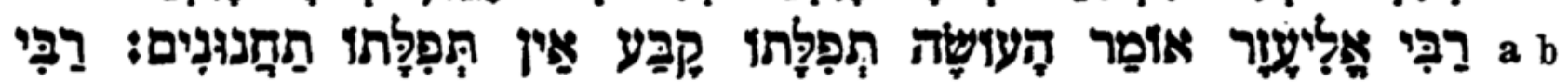

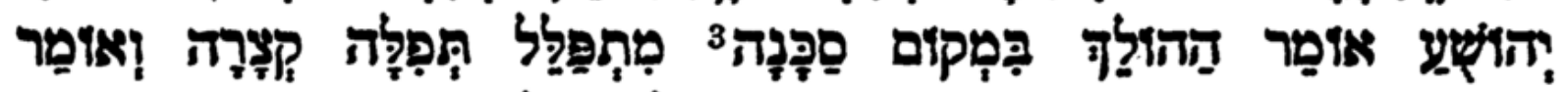

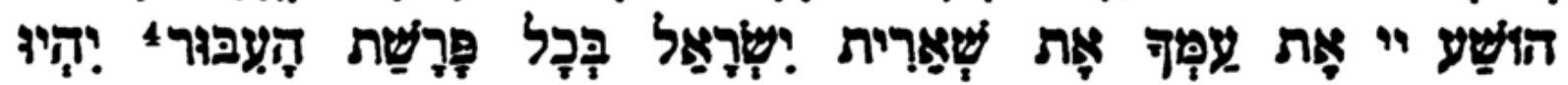

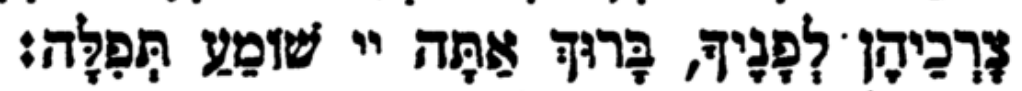

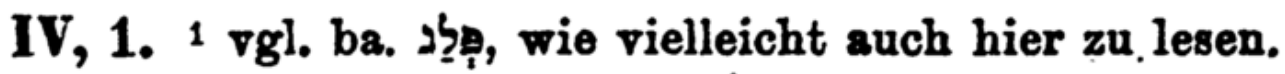
2 festgesetzte zeit. 3 vgl. bh. ?

4 zugabegebet, vgl. IV, 7.

2. 1 hineingehen.

4 anstob.

5 vgl. bh. תฺุ
2 lehrhaus. 6 beruf.

3-4. 1 wörtlich: nach art von, also : ein das' y' zusammenfassendes gebet. ${ }^{2}$ geläufig. zu nehmen: abschnitte der reise.

unreinheit gemachte abschweifung. - 4. מהרהר sc. über das šemá.

IV, 1-V, 5: Abgrenzung der drei täglichen gebetszeiten und kasuistik des achtzehngebets.

IV, 1. Die 3 gebetszeiten, vgl. zu dieser alten, in anlehnung an den tempelkult entstandenen sitte Ps. 55, 18 u. Dan. 6, 11 u. 14; auf beide stellen beruft sich die Tosephta Ber. § 6. Zur parallelität der kultischen handlung und des gebets vgl. Ps. 5, 4 und 141, 2. Zu den מọp vgl. heft 58, s. 21 ff.; sie haben ihr kultisches vorbild in den musaphopfern für die sabbathe und festtage, vgl. Num. 28-29.

2. Abschweifung (ad vocem gebet).

3-4. Übor die pflicht des achtzehngebetes (3) und 


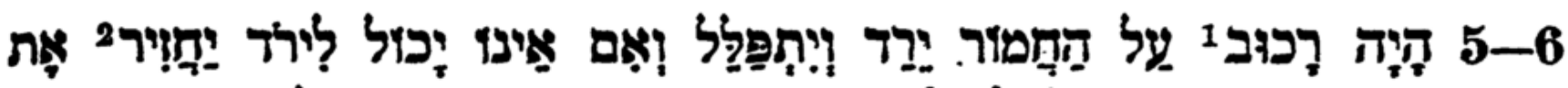

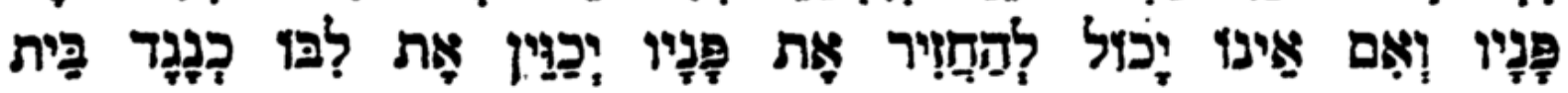

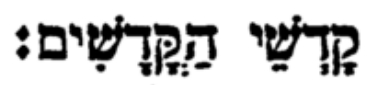

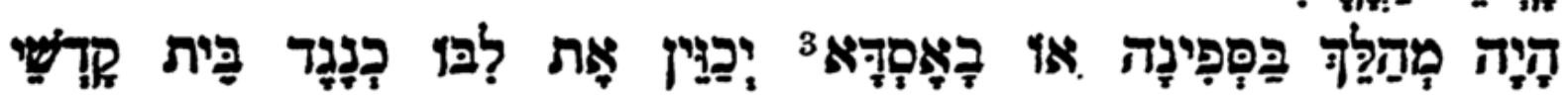

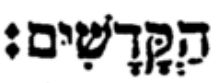

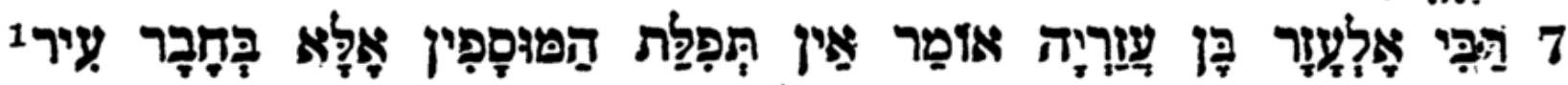

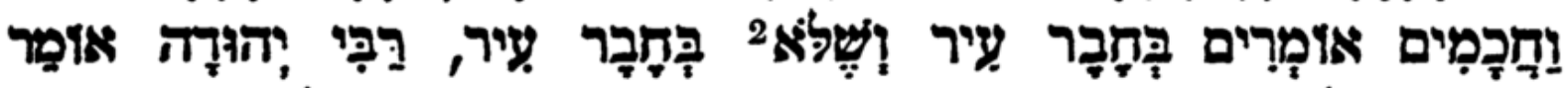

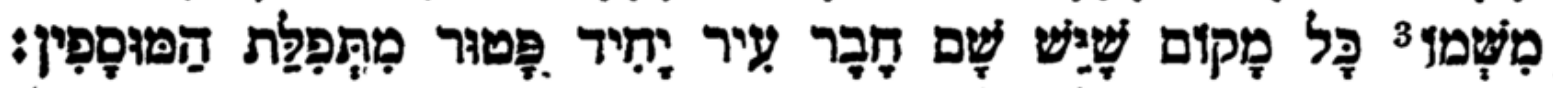

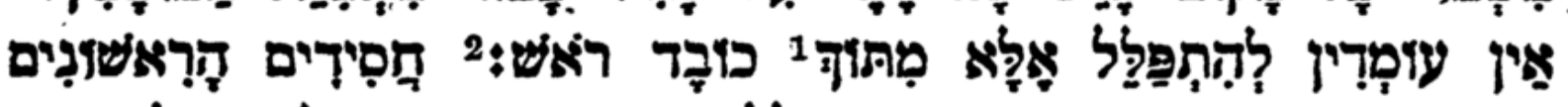

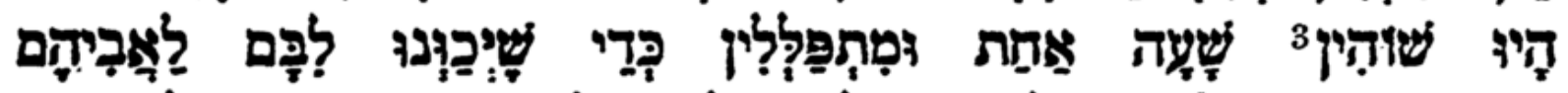
登

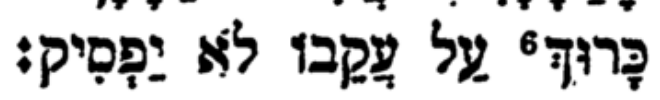

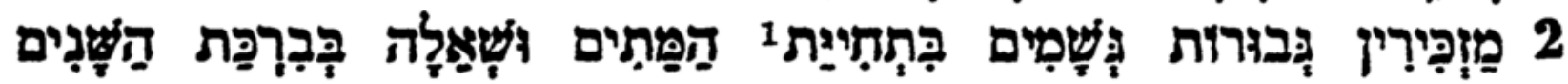

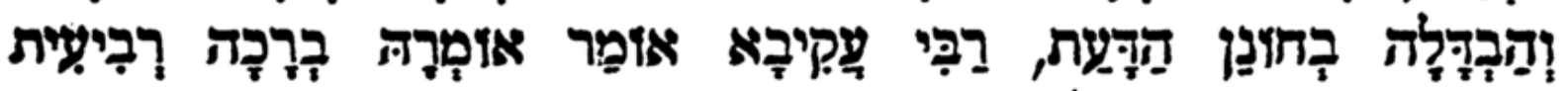

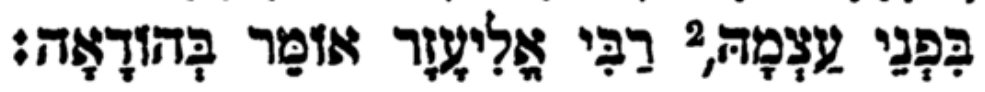

5-6. 1 verwendung des part. pass. in aktiver bedeutung wie im aramäischen; ebenso wird מุ๊ gebraucht. 2 hinwenden (sc. nach Jerusalem). $\quad 3$ wohl $=\sigma \chi \varepsilon \delta i \alpha$.

7. 1 lokale synagogengemeinschaft. 2 und nicht. 3 sc. Rabbi Eleasars.
V, 1. 1 infolge, mit.
2 ernste stimmung.
3 weilen,

warten.

1 selbst wenn.

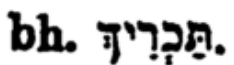

2. 1 auferweckung.

2 für sich allein.

wann es durch eine kurze benediktion ersetzt werden darf (4b); dazwischen eine 2.abschweifung ad vocem gebet (4 a). - Tos. Ber. $\$ 7$ bietet weitere vier beispiele für eine המלה 'y vil. außerdem heft 58, s. 10 u. 20.

5-6. Wie man sich auf reisen zu verhalten hat. Zur sitte der gebetsrichtung (Kibla) vgl. Dan. 6, 11. - 5ינו יכול לי sc. weil er keinen begleiter hat, der das tier bewacht. 6. Der grund ist, weil er sich nicht $\mathrm{za}$ orientieren vermag.

7. Über die zugabegebete, vgl. IV, 1 u. heft 58 , s. $21 \mathrm{ff}$.

V, 1. Zweite abschweifung ad vocem gebet, vgl. dazu II, $1 \mathrm{~b}$ und $\mathrm{c}$.

2. Über die zusätze zum šemone 'esre und die habh- 
3

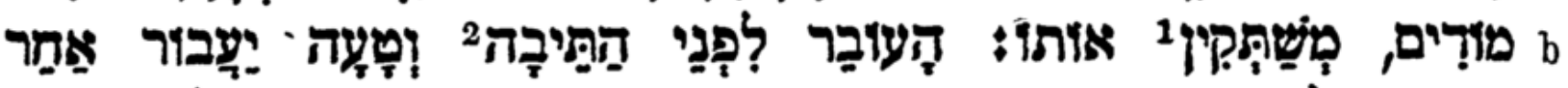

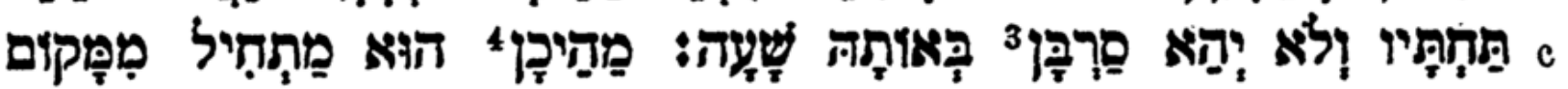
:

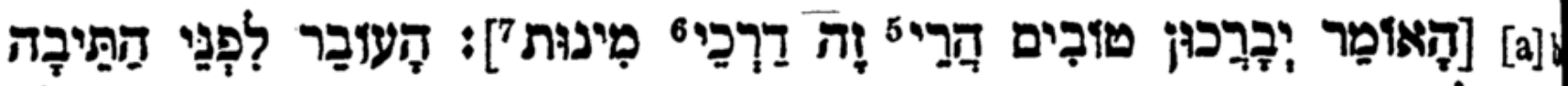

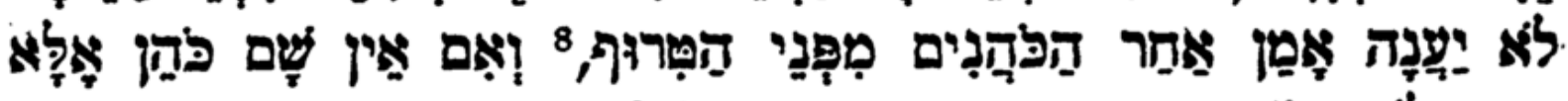

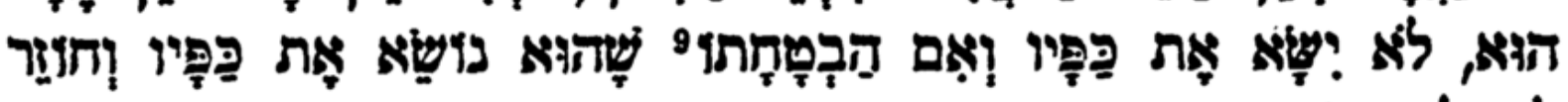

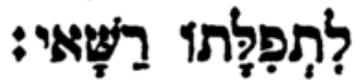

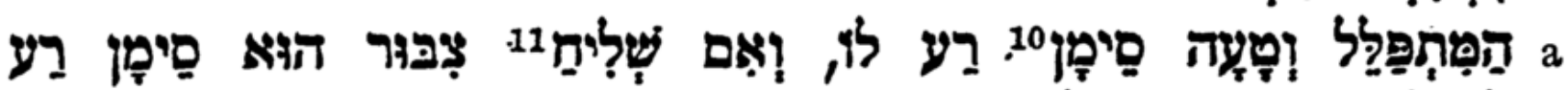

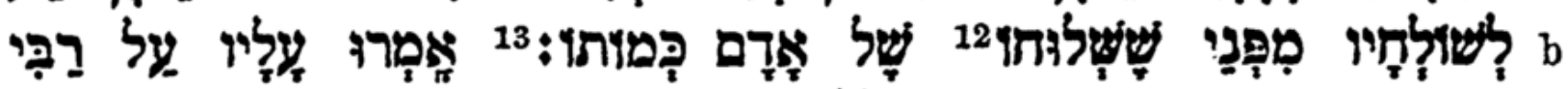

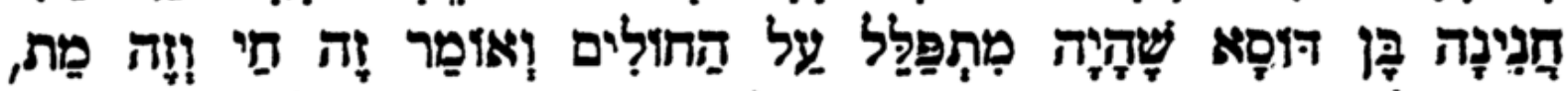

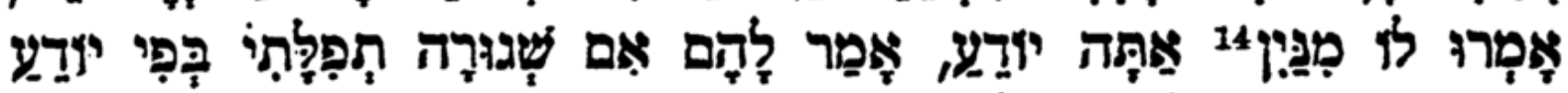

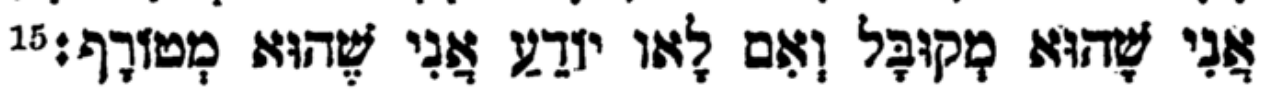

3-5. 1 intensivstamm in kausativer bedeutung. 2 term.

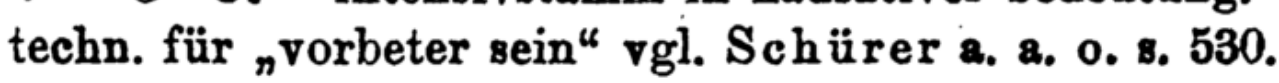
$3 \mathrm{vgl}$. bh סָר. 7 ketzerei.

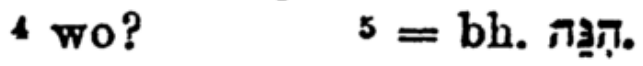
8 eine art von. $\mu \varepsilon i \bar{o}$.

8 verwirrung. 9 vertrauen zu sich. $10 \sigma \eta-$ dierendes pronomen wie so häufig im späteren hebräisch. $13=b h$. . 14 woher? 15 wörtl.: weggeworfen werden.

dala, vgl. heft 58, s. 11 u. 26. - Nach der gemara zur stelle (Ber. fol. 33a) ist. der grund dafür die innere verwandtschaft der bitten. -

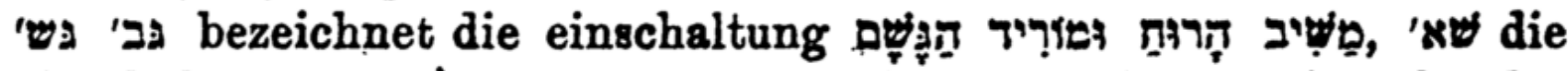

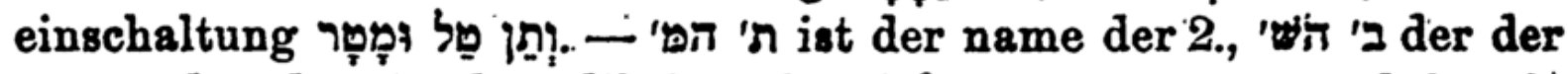

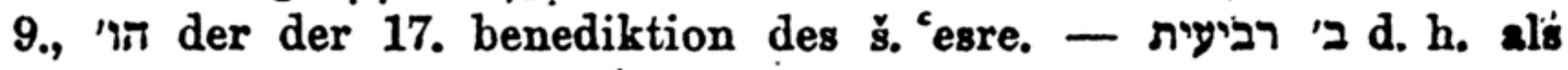
mittelstück der sog.

3-5. Über unerlaubte benediktionen (3a) und irrtümer beim beten $(3 b-5) .-3$ a) die gemara giebt folgende erklärung dazu: "על קו צופור ו וגו (vgl. Deut, 22, 7) nicht,-weil dadurch neid in der schöpfung erregt werde oder weil dergleichen nicht dem ernst des im gesetze offenbarten wesens Gottes entspreche, על טיב ' וג nicht, weil das den anschein erwecke, als danke man Gott nur für das gute und nicht auch für die übel (vgl. IX, 2 a. e.); מודים מודים nicht, weil es gegen die einheit der gottesvorstellung verstößt

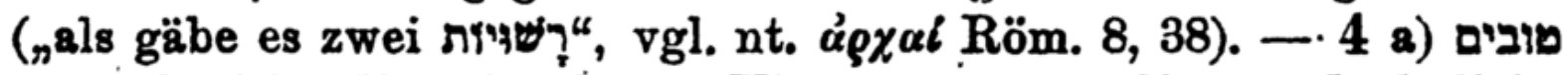
sc. und nicht die schlechten. Vielleicht waren diese und ähnliche gebete wegen ihres dem evangelium verwandten geistes verpönt. 
VI,1a

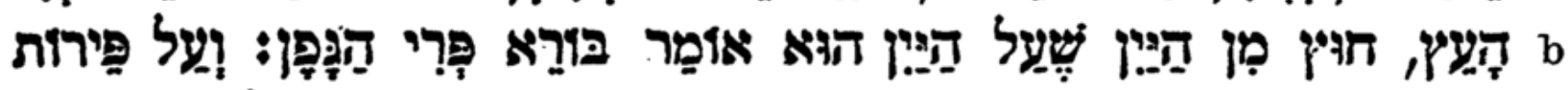

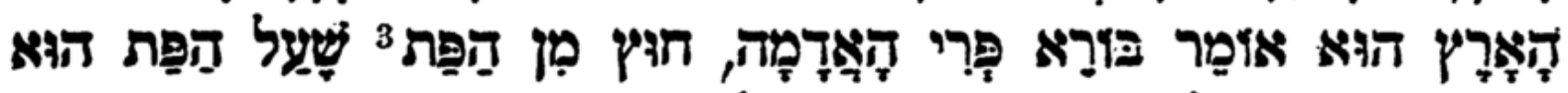

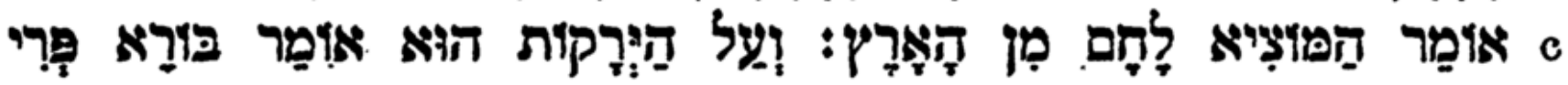

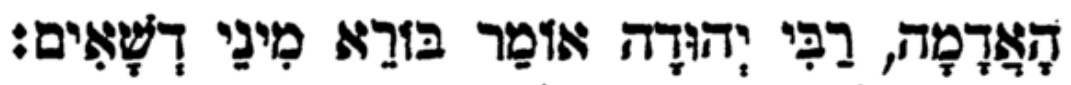

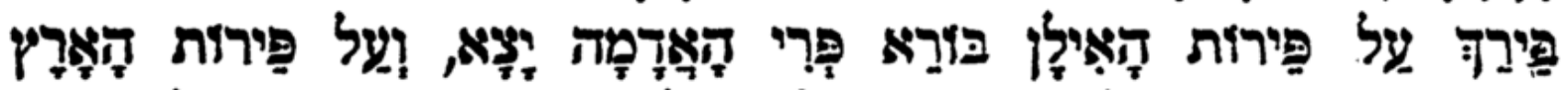

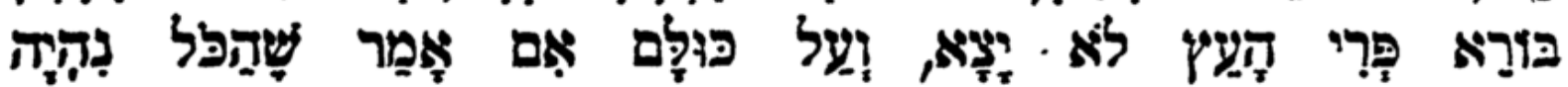

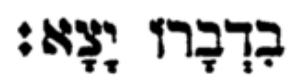

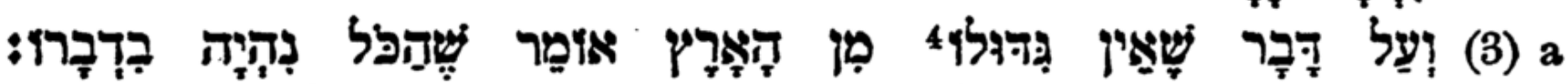

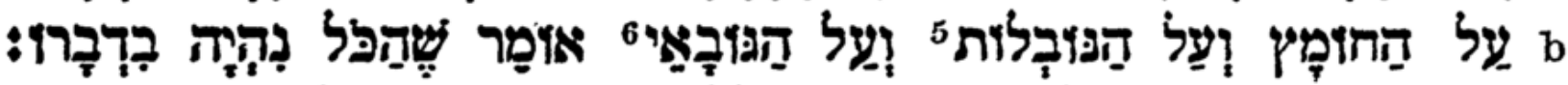

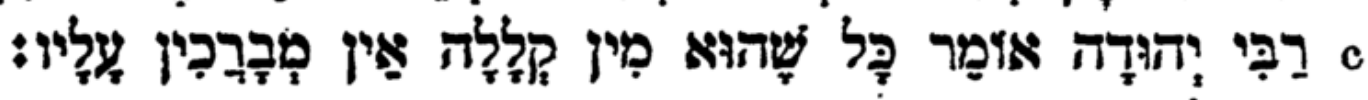

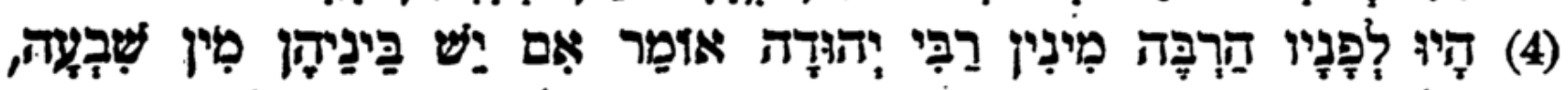

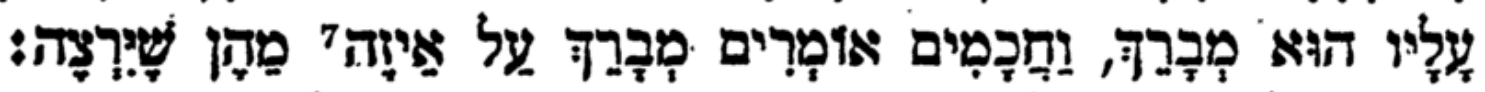

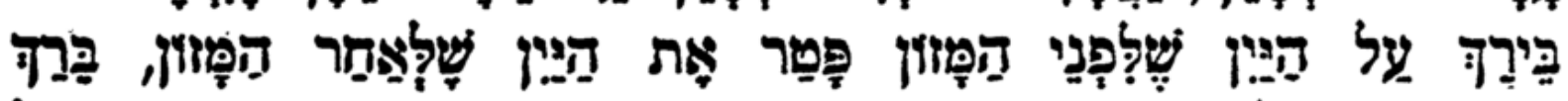

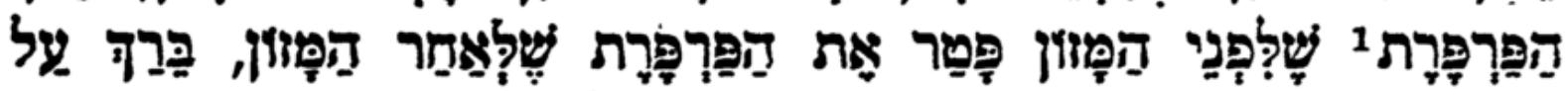
VI,

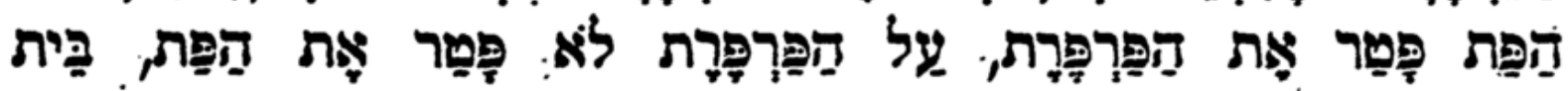

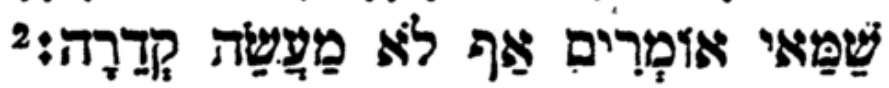

VI, 1-4. ${ }^{1}$ auf welche weise? $\quad 2$ plural von ירָ̣. $\quad 3=b$. . 4 wachstum. 5 unreif abgefallenes obst. 6 vgl. bh. 'כits. 7 welche.

5-8. 1 zukost. 2 topfspeisen (grütze u.`a.).

b) vgl. dazu heft 58 s. 19 zu $18 \mathrm{i}$ und Schürer a. a. o. s. $529 \mathrm{ff}$. Der .rorbeter sprach einem der anwesenden priester die teile des aronitischen segens vor. Aus unserer stelle darf man übrigens schließen, $\mathrm{da} B$ die priester beim synagogalen amt des vorbeters dieselben vorrechte hatten, wie die theologen bei der synagogalen predigt. - Über den priestersegen vgl. Schürer a. a. o. s. 535f. vgl. Schürer a. a. 0. s. 515 .

VI, 1-IX, כ. Die kasuistik der segenssprüche, vg], dazu Schürer a. a. o. s. 571f., Bousset a. a. o. s. v. tischgebet.

1. VI, 1-4. Segenssprüche über die verschiedenen vegetabilien. - 1 a) ein solcher segensspruch lautet vollständig מין קללה (3ezeichnet wahrscheinlich verdorbene oder im wachstum behinderte früchte; auf sie ist gleichsam ein fluch gefallen. $-4 \mathrm{zu}$ den 7 arten vgl. Deut. 8, 8. 


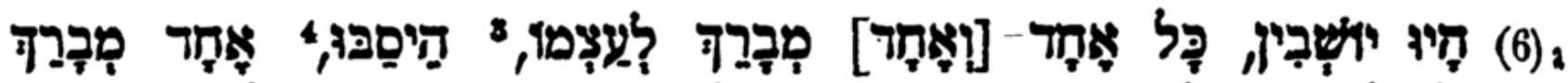

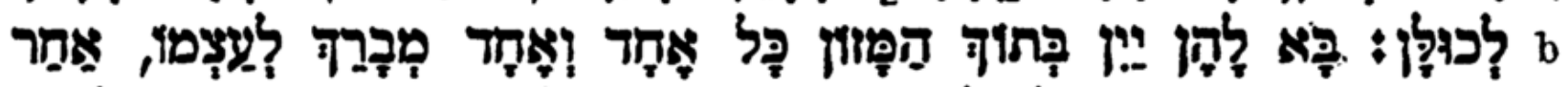

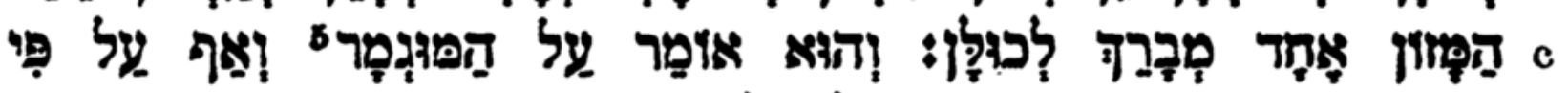

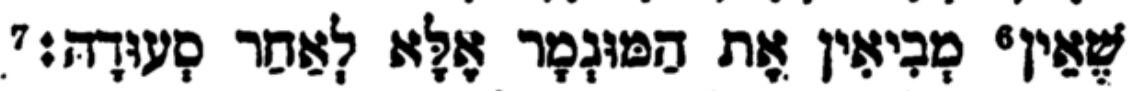

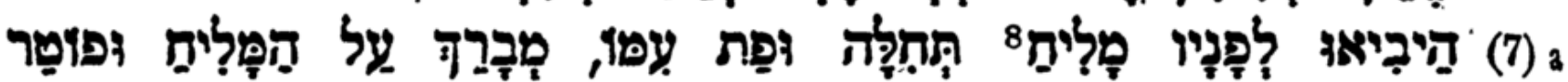

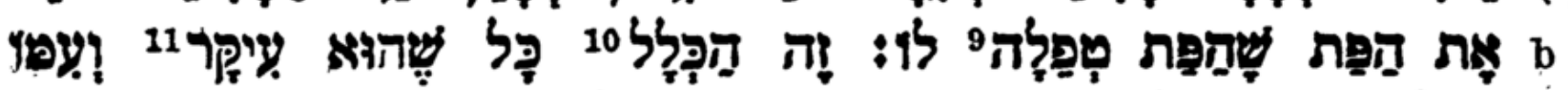

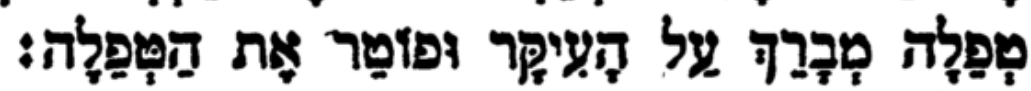

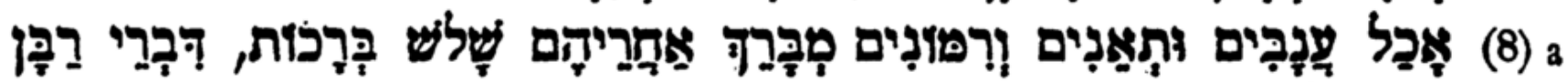

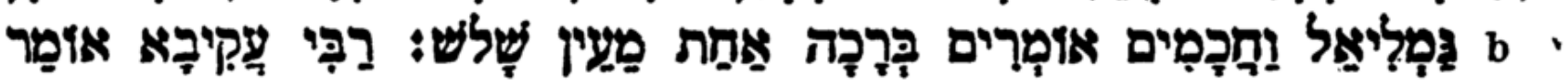
c

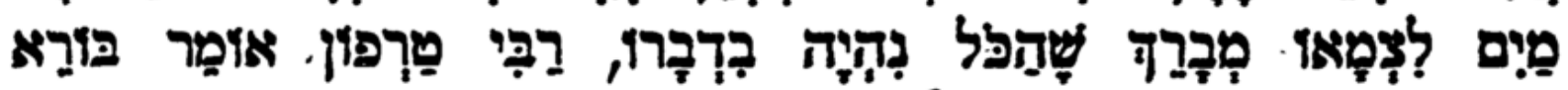

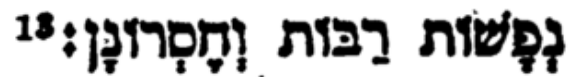

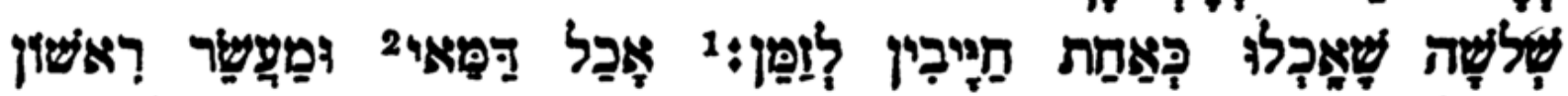

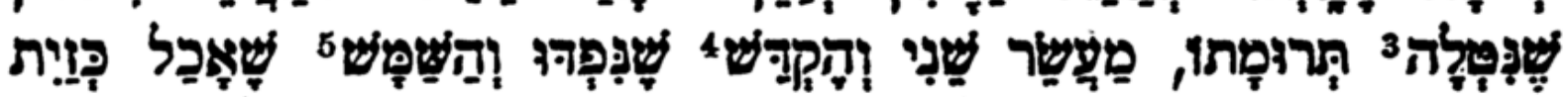
VII,

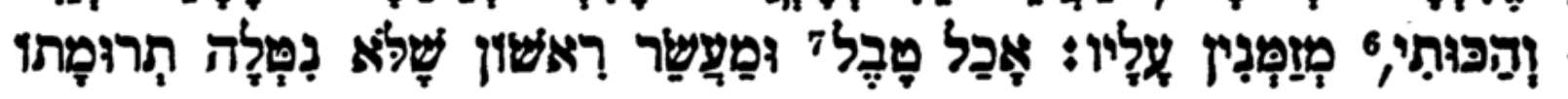
a b 3 vgl. I, 3 c. $4 \mathrm{zu}$ tische liegen. 5 räucherwerk, mit dem das zimmer nach tisch durchduftet wurde. o obgleich. 7 mahlzeit. 8 eingesalzenes, wohl zur anreizung zum essen und trinken. 10 regel. 9 wörtl.: hinzufügung, also soviel wie nebensache. gekochtes gemüse (kohl). 13 bedürfniß.

VII, 1-5. ${ }^{1}$ gemeinsam das tischgebet sprechen resp. daza auffordern. 2 eigentlich: $z$ weifelhaftes, dann im bes.: früchte, über deren gesetzlich geforderte verzehntung zweifel besteht; danach name eines mišnatraktats $(I, 3)$, der diese materie behandelt. 3 entrichten. 4 geweihtes. 5 diener. 6 samaritaner. 7 zehntpflichtige, aber noch nicht verzehntete früchte.

2. VI, 5-VIII, 8. Die kasuistik des tischgebets: a) VI, 5-8. Worüber und wann die benediktionen zu sprechen sind. - 5 a) das zutisch liegen giebt dem essen erst den charakter der gemeinsamen mahlzeit. c) והוה sc. derselbe, der den segensspruch für alle gesprochen hat. Die gemara sagt: $n$ weil er zuerst nach dem essen die hände gewaschen hat ${ }^{\mu}$. - לאחר סעודה: also auch nach dem tischgebet am schlu $B$ des essens. Die benediktionen sollen möglichst von ein em gesprochen werden. - 8c) der gegensatz ist nach der gemara: wasser zum herunterspülen eines bissens, der in der kehle stecken geblieben ist. 


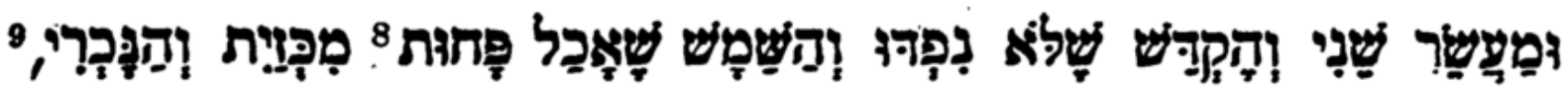

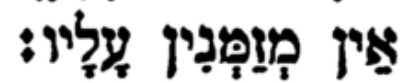

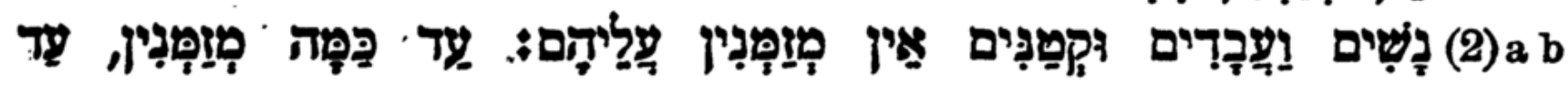

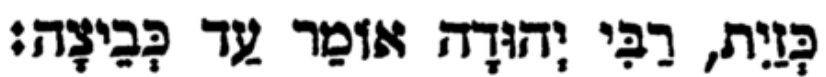

a

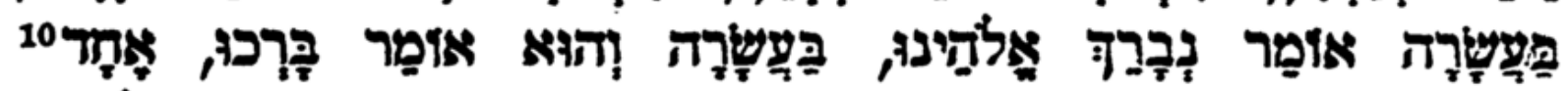

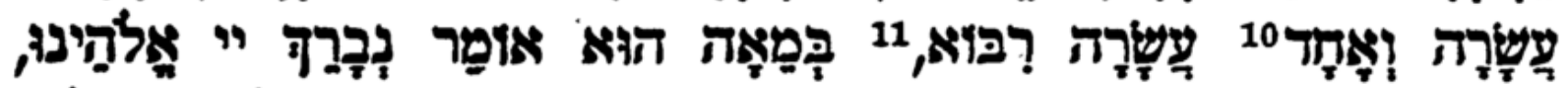

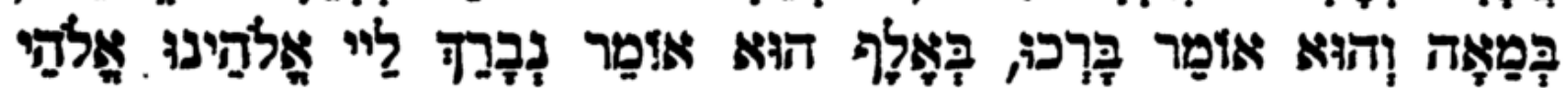

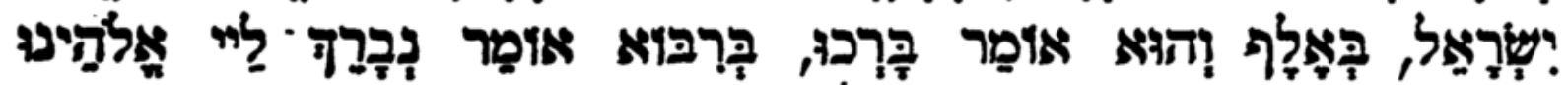

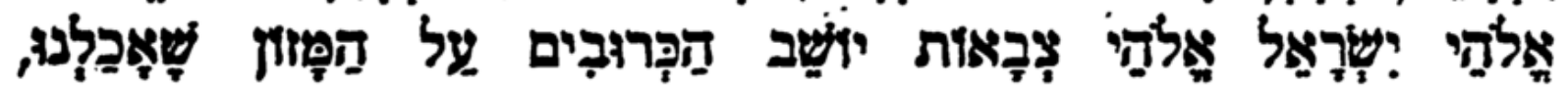

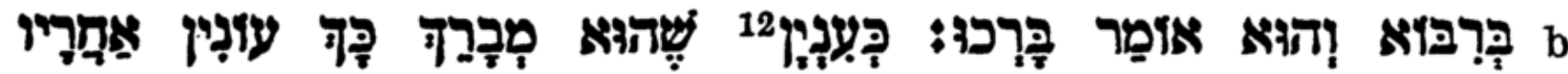

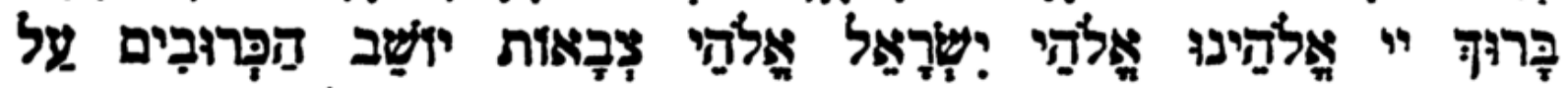

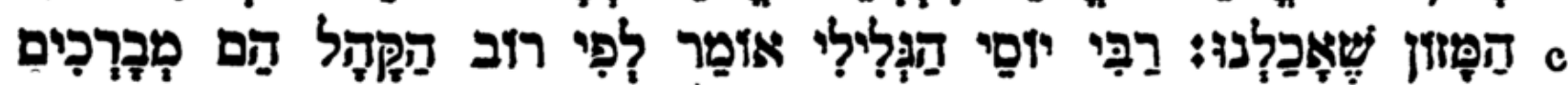

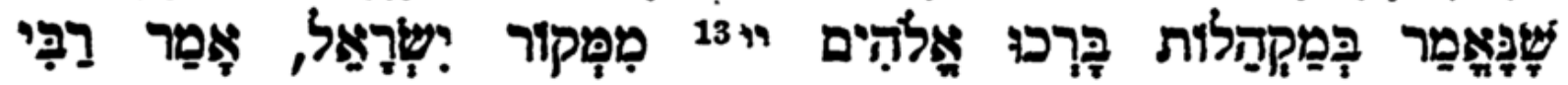

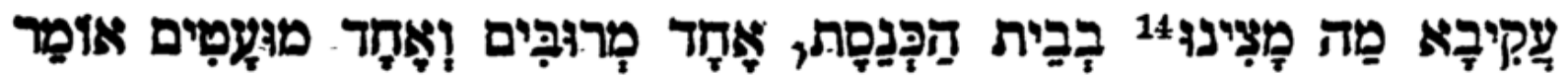

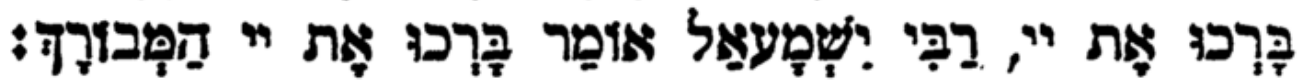

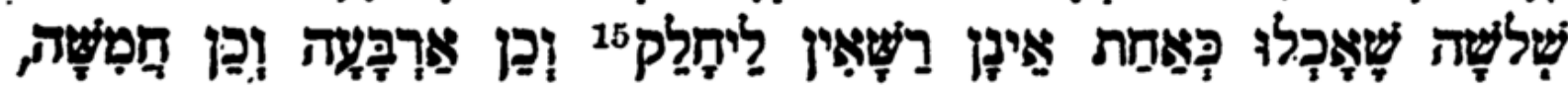

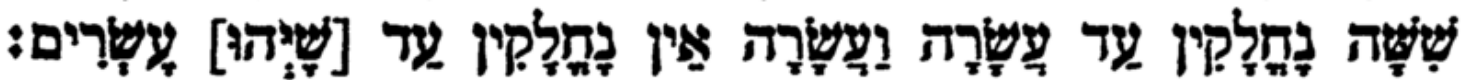

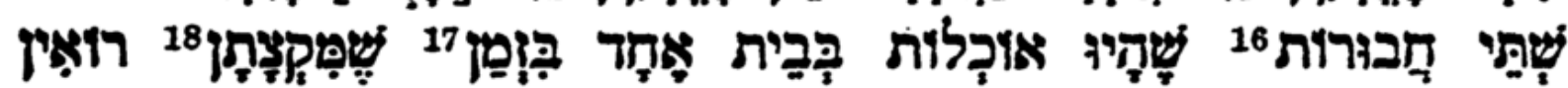

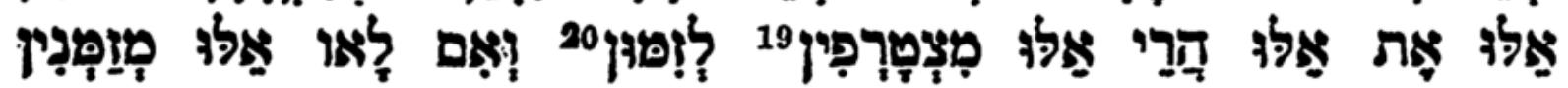

8 weniger.

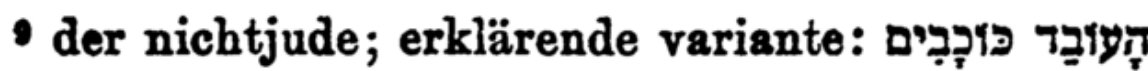
תitizin, in Pinners ausgabe des traktats Bab. Talm. I. 10 sowohl - als auch. 11 vgl. bh. u. ba. 197. 12 eodem modo. 13 in \% 68, 27 steht 14 übergang der ${ }^{\prime}$ in in ist häufig. 15 II sich trennen. 16 gesellschaft. 17 wenn. 18 teilweise (wörtl.: einen teil von ihnen). 19 sich verbinden. 20 gemeinsames tischgebet.

b) VII, 1-5. Wer am tischgebet teilnehmen darf (1-2) und wie dabei zu verfahren ist ( $3-5 a)$; 5 b geht auf VI, 6 b zurück und bildet den übergang zum folgenden abschnitt. I b) zu דפר vgl. den grundsatz Lev. 27,30 , zum 1. und 2. zehnt u. zur תרומר vgl. Num. 18, 21 ff. 25 ff., Deut. 14, 22 ff. 26, $12 \mathrm{ff}$. Über diese schwierige materie handeln 3 traktate der mišna, תומาภุ,

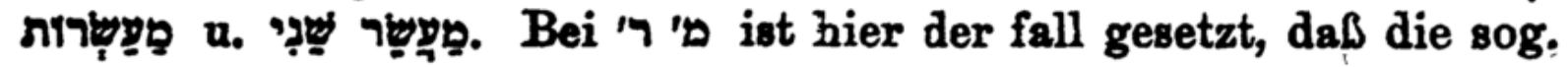




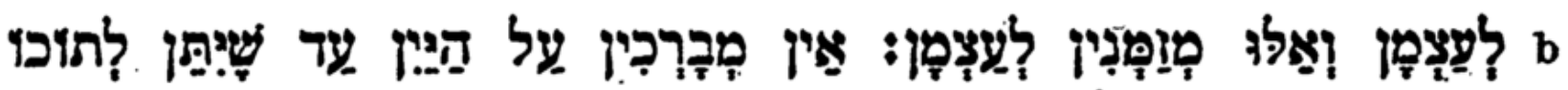

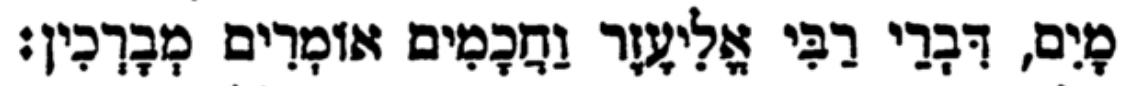

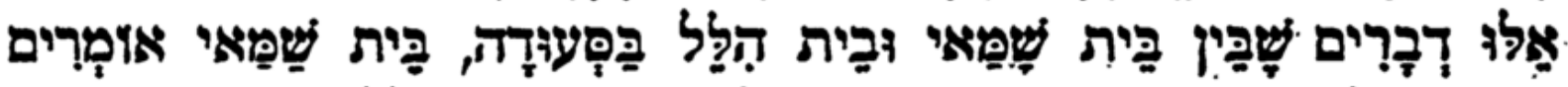

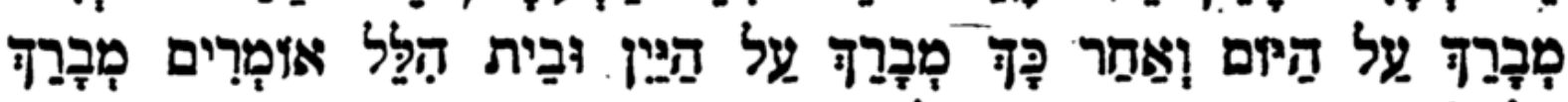
VIII, $1-8$

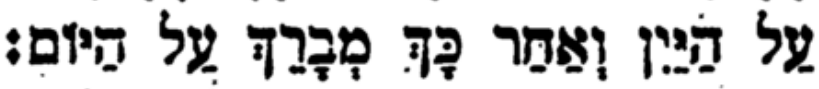

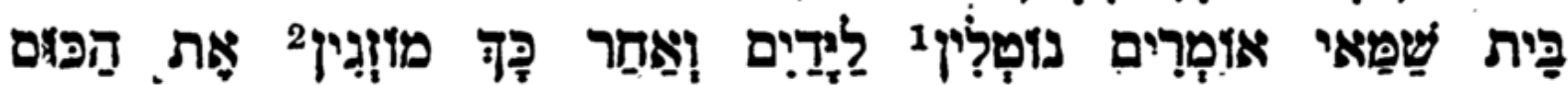

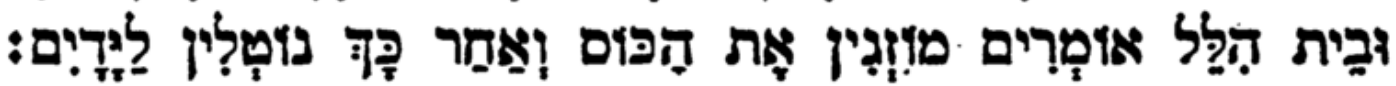

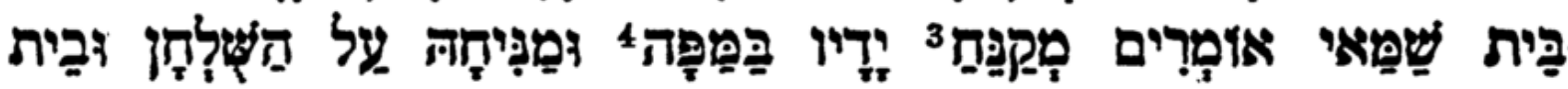

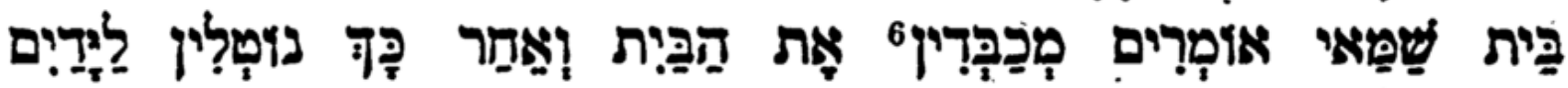

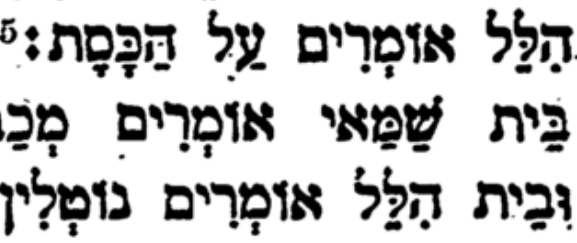

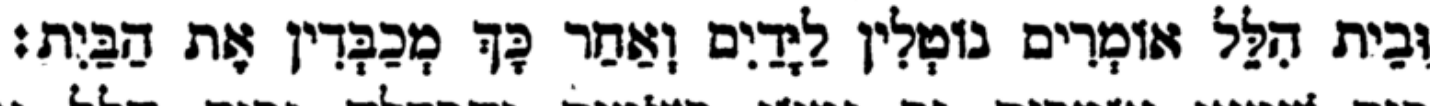

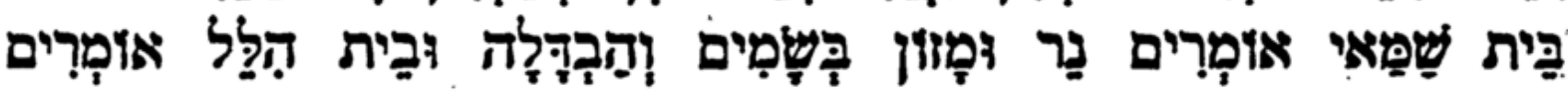

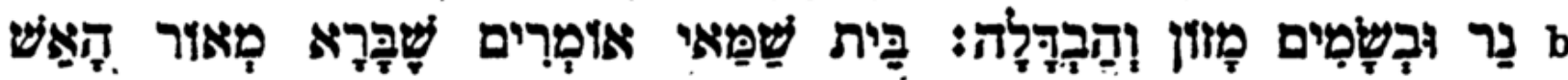
(5) $a$

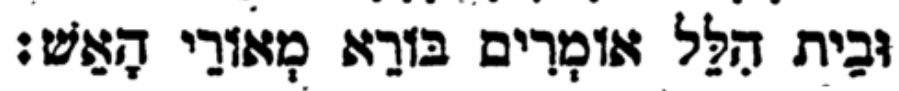

VIII, 1-8. ${ }^{1}$ die hände waśchen. 2 mischen, vgl. bh. מָ̣. 3 abwischen. 4 mappa, nach Quintilian I 5, 57 ein punisches wort: $\quad{ }^{5}$ polster. $\quad 6$ פבד III reinigen, fegen.

priesterhebe noch nicht abgesondert, bei ' הק ' setzlich gebotene aufschlag von $1 / 5$ noch nicht gezahlt worden ist. 2 b) עד נd. h. wieviel speise muß der zur teilnahme am tischgebet berechtigte gegessen haben. - 3 a) xili sc. dem, der zum gebet auffordert und es spricht. - 3, 10, 100 etc. sind gleichsam selbständige gebetsgomeinschaften, die auch ohne den 4., 11., 101. etc. den segensspruch sprechen können; daher der unterschied in der aufforderungsformel. Da aber erst 10 nach rabbinischer lehre eine ngemeinde" ausmachen, darf der gottesname erst im tischgebet von 10 gebraucht werden. Darauf bezieht sich die parenthese עשלרה וגו' Mit der größe der gebetsgemeinschaft wächst die zahl der appositionen zum gottesnamen. $\quad$ c) der synagogale ritus scheint hiernach im 1. u. 2. jhd. einfacher gewesen zu sein. 4 erst 6 können sich wieder in selbständige gebetsgemeinschaften. auflösen. 10 bilden eine untrennbare kultische einheit, s. 0 .

c) VIII,1-8. Hierher gehörige kontroversen $z$ wischen der 'schule Hillel's und Schammai's. - In diesem abschnitt ist $\S 6$ (und vielleicht auch 8 b) ein späterer zusatz.

1) היז: nämlich den sabbath oder feiertag; gemeint ist das sog. ש. der weihesegen beim anbruch der feiertage. Die gemara 


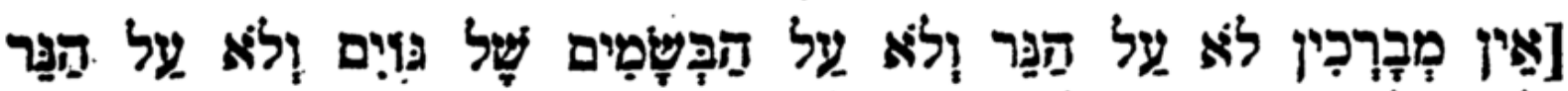

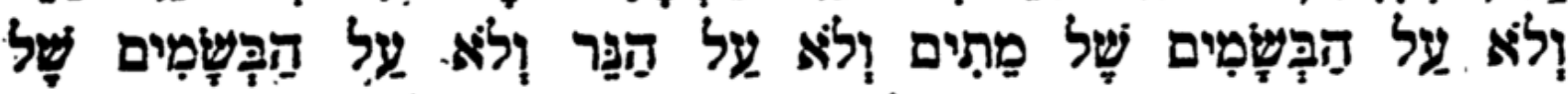

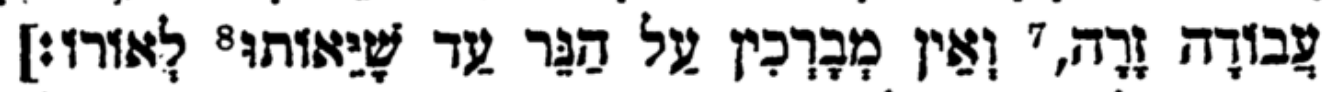

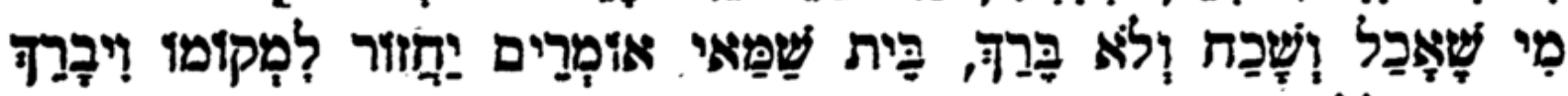

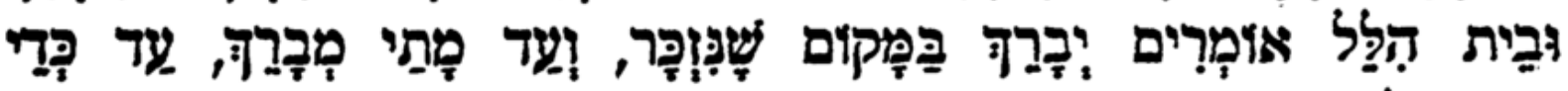

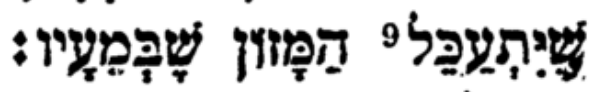

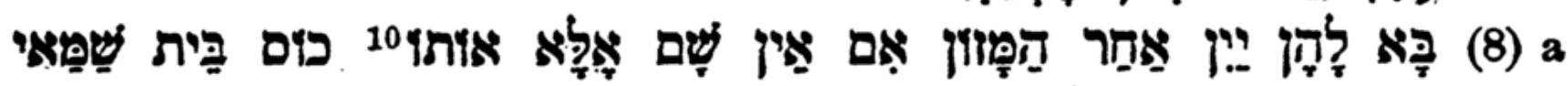

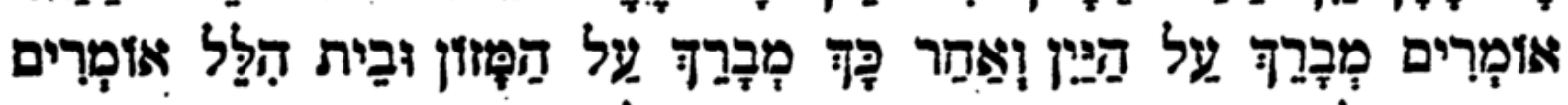

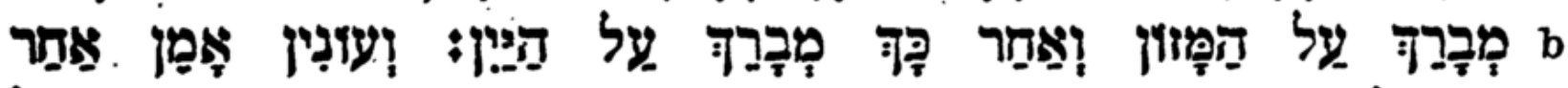

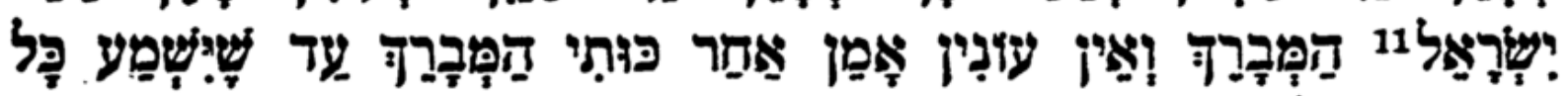

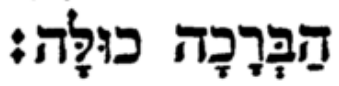

7 götzendienst d. h. heidnischer kult und heidn. kultgegenstände. 8 benutzen. 9 verzehrt ( $=$ verdaut) werden. $\quad 10$ als demonstrativpronomen gebraucht: jen er b., d. h. hier der nach dem essen gebrachte (vgl. Marc. 14, 17 ff., bes. Luc. 22, 20). $11 \mathrm{~d}$. h. ein israelit.

begründet Hillels anschauung mit den.worten: der wein verursacht die weihung (des tages), d. h. ohne den wein (resp. das brot) kann. man das vitp nicht sprechen.

2) u. 3) beziehen sich auf das händewaschen vor tisch. Hillels und Schammai's forderungen bezeugen das peinliche streben beider schulen nach ritueller reinheit. Dieser komplizierten materie, bei der die verschiedenen grade der verunreinigung eine rolle spielen, sind mehrere traktate der mišna gewidmet, vgl. tr. טָדָרז und ם? דיָ, Strack 8. 60 u. 62.

4) u. 5) beziehen sich auf den ritus nach tisch. Das „haus" ist a potiori bezeichnung für den raum, in dem gegessen wurde resp. den tisch und den platz um den tisch. - 5a) handelt von der reihenfolge der benediktionen am sabbath; die a dienen zur vertreibung des eßgeruchs. $\quad 5 \mathrm{~b}$ ) ist wieder typisch für die rituelle peinlichkeit: die vielen strahlen im lichte müssen sich gleichsam in der lichtbenediktion reflektieren.

6) ist ad vocem נישמים eingefügt. Wo nichtjuden zu tisch sitzen, ist immer עבודה זרה zu befürchten; bei einer leiche ist der grund des verbots nach der gemara die völlig andere bedeutung von licht und wohlriechenden kräutern: sie dienen da "zur ehre", resp. num den geruch $z u$ vertreiben ${ }^{\star}$. Vielleicht steckt aber alter 


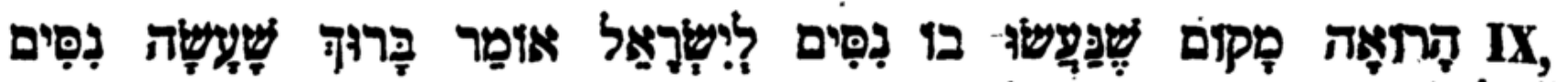

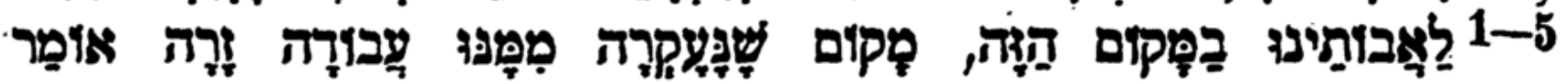

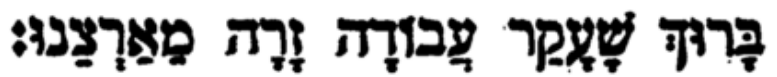

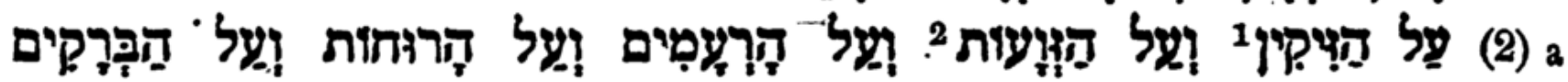
b

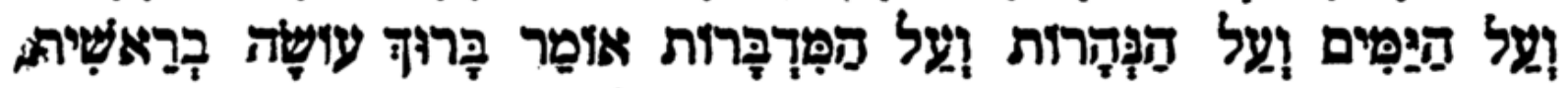

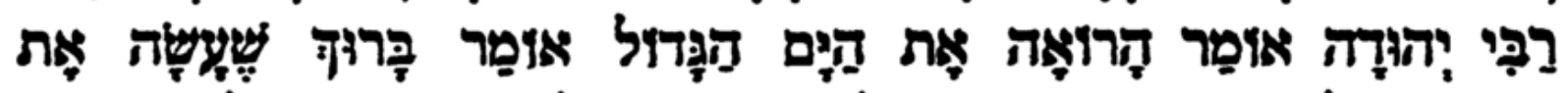

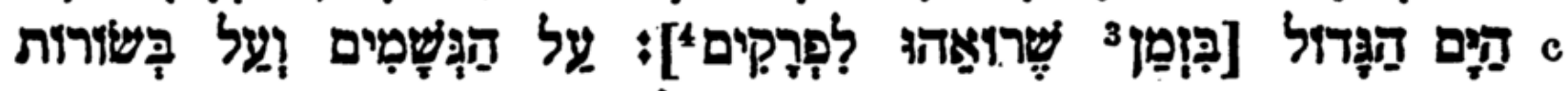

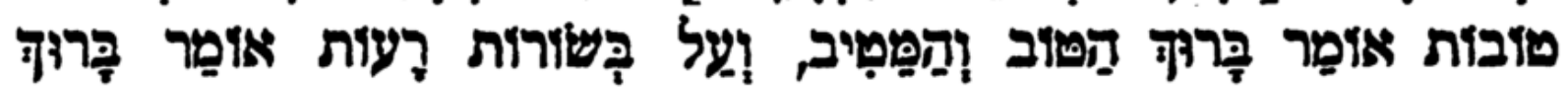

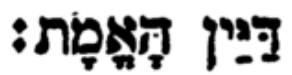

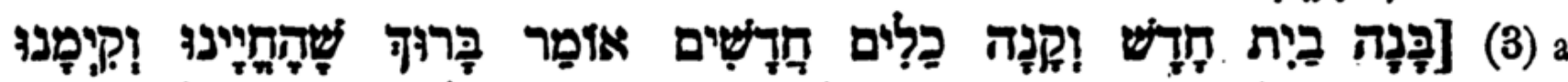
b

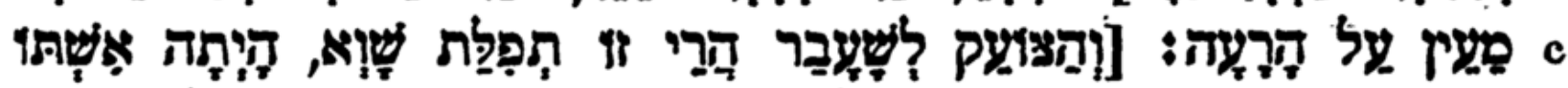

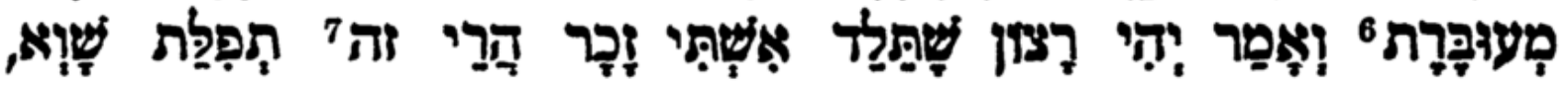

IX, 1-5. 1 vgl. bh. תip'!

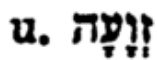
3 vgl. VII, 5 a. der gemara) bis zu 30 tagen. עב III.

2 vgl. bh. wurzel yil; vgl. הצֶ? 4 wörtl.: in abschnitten d. $h$. (nach 5 vgl. IV, 3. 6 vgl. bh. lesen sein.

aberglaube dahinter. - שי d.h. wohl ursprünglich bis man dabei deutlich sehen kann.

8 a) gemeint ist der sog. für das tischgebet nach dem essen notwendig ist, vgl. o. zu § 1 .

3.IX,1-5. Benediktionen bei verschiedenen anlässen, nämlich beim anblick von orten (1) und phänomenen, die gottes wunderbare kraft erweisen (2a u. b), und beim eintreffen von nachrichten $(2 \mathrm{c}-3)$. In diesem abschnitt lassen sich deutlich als zusätze erkennen $\S \S 3$ a, 3 c, 4 u. 5 b. $\S 4$ ist wahrscheinlich eine erst durch $3 \mathrm{c}$ hervorgerufene digression, also einschub im einschub, $\$ 5 \mathrm{a}-\mathrm{c}$ ist inhaltlich sehr alte überlieferung, aber dem ursprünglichen zusammenhang wohl fremd. $5 \mathrm{~d}$ endlich iat ein aus lose aufgereihten schriftzitaten bestehender abschluß des ganzen. - Die hier erwähnten benediktionen beginnen allesamt mit den worten ..... פריצ

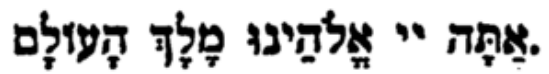

2 b) Die letzten worte sind vielleicht späterer zusatz. Der grund für R. Judas ausdrucksweise ist nach rabbinischer exegese die unvergänglichkeit des meeres, während die andere durch den 


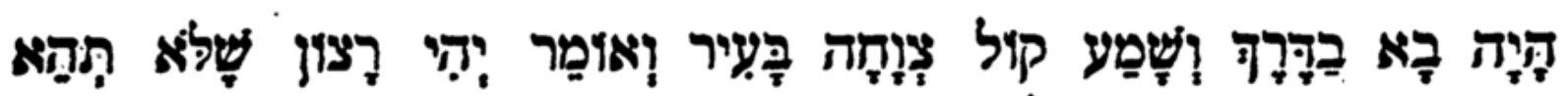

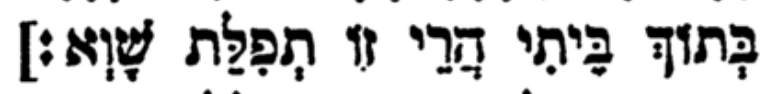

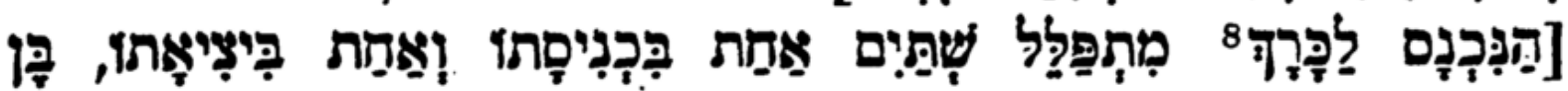

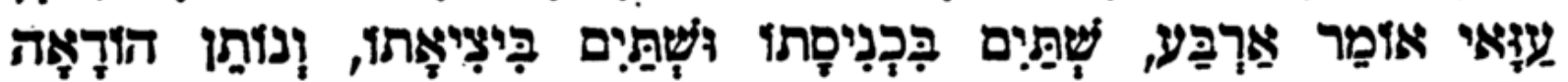

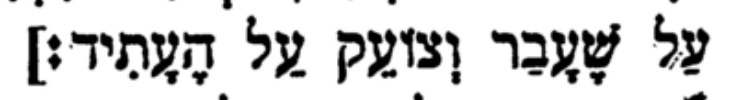

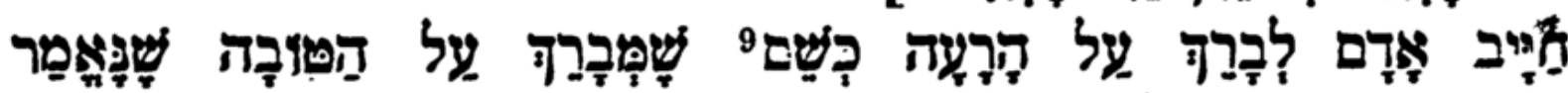
(5) $a$

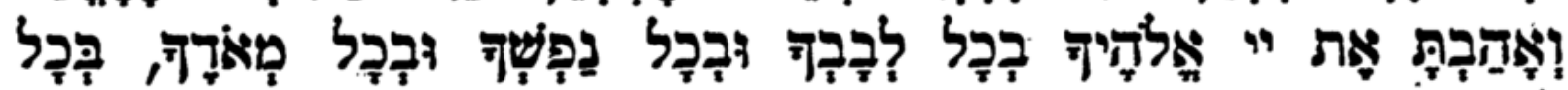

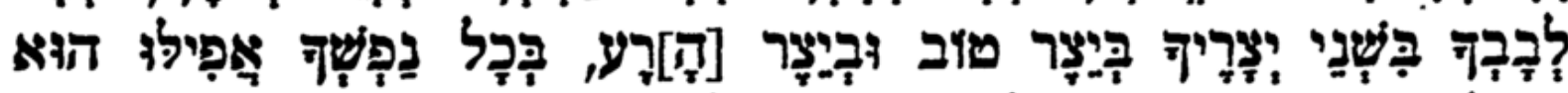

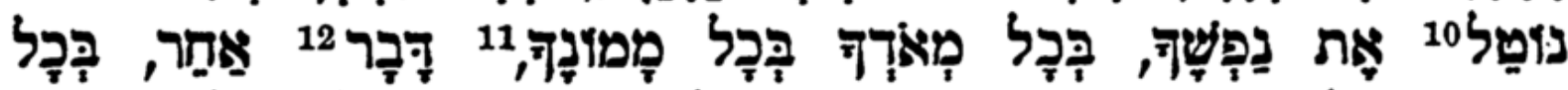

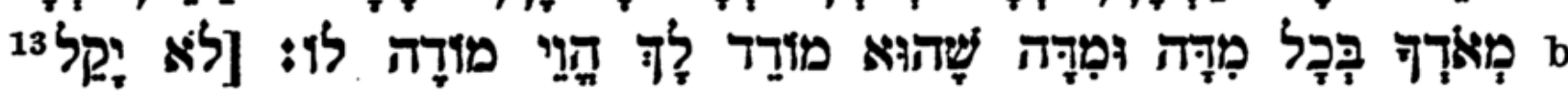

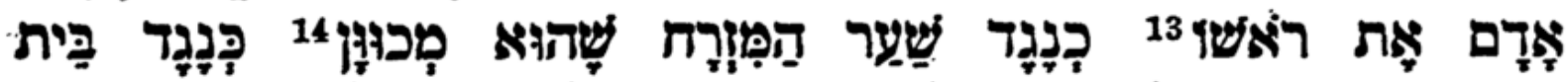

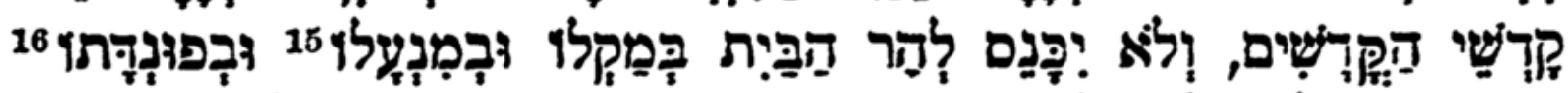

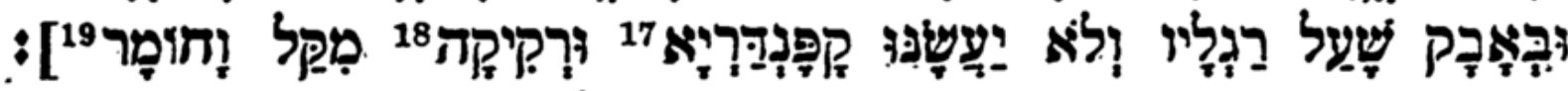

8 stadt. 9 wie. 10 wegnehmen. 11 vermögen. $12 \mathrm{er}$ klärung. 13 leichtfertig sein. 14 genau. 15 schuh. 16 funda (geldbeutel). 17 compendiaria (sc. via). 18 ausspeien. $\quad 1.9$ um wieviel mehr (formel für den schluß a minori ad majus):

umstand geboten ist, daß die genannten schöpfungswerke in ewigem werdeproze $\lesssim$ sind. - c) Die zusammenstellung von regen und guten nachrichten ist echt orientalisch.

3 b) Der ursprüngliche sinn ist doch wohl derselbe wie in 5 a, es dürfe kein unterschied gemacht werden in der frommen hinnahme von glück und unglück (vgl. Hiob 2, 10); so auch die gemara zu 5 a (fol. $60 \mathrm{~b}$ ), wo Rabbi Jehudas ausspruch zitiert wird: nder mensch soll es zu unserer stelle (fol. 60 a), die den satz durch das beispiel von der überschwemmung die, scheinbar ein unglück, ein segen für das ackerland ist, und von einem fund, der, scheinbar ein glück, zum unglück werden kann, illustriert. Daher Goldschmidt's übersetzung: nman benedeiet für das schlechte, das mit gutem zusammen: fällt" etc.

c) הציעוy sc. zu gott im gebet.

5 a) Dt. 6,5. - Zur lehre von den beiden "trieben ${ }^{*}$ im menschen vgl. Bousset a. a. o. s. $462 \mathrm{ff}$. - Die erklärung stammt von Aqiba, von dem die gemara zur stelle (fol. 61 b) erzählt: die stunde, wo man R. A. zur hinrichtung führte, war gerade die zeit zum beten des šema ; man riß sein fleisch mit 


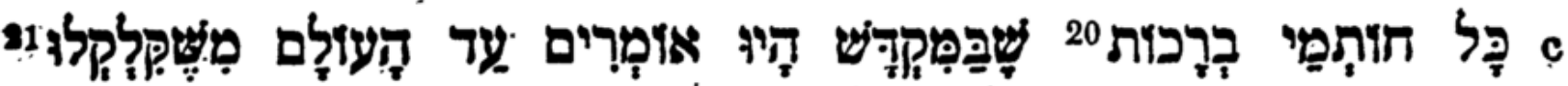

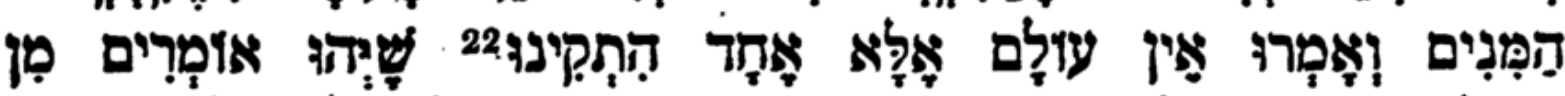

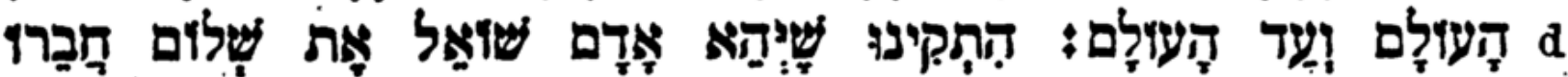

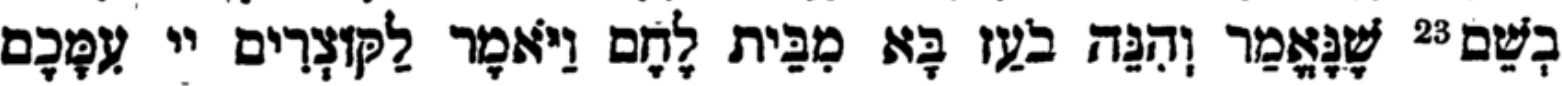

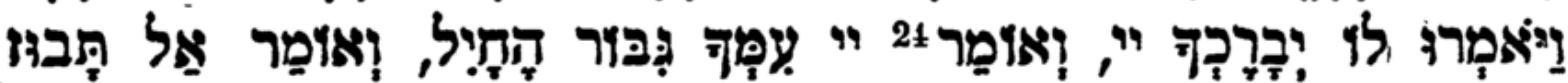

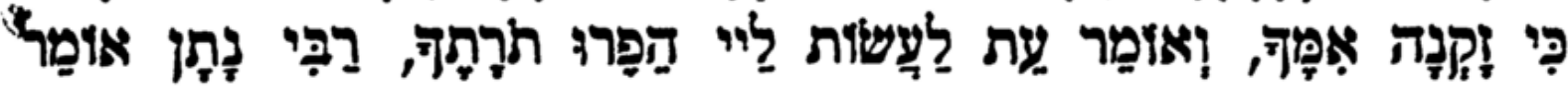

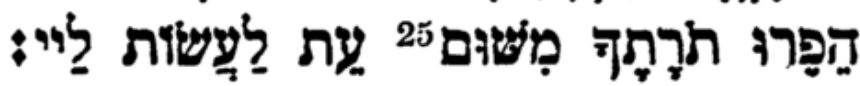

20 vgl. I, 4. stimmen.
21 verderben (sc. durch ihre ketzerei).

22 be23 sc. gottes.

24 sc. die schrift, vgl. die neutest. terminologie Röm. 9, Hebr. 8 u. ö. $\quad{ }^{25}$ weil; gewöhnl.

eisernen kämmen, er aber "nahm das joch des himmels auf sich" (vgl. o. II, 2). Als seine schüler darüber erstaunten, sprach er: nmein ganzes leben grämte ich mich über den schriftvers $n$ mit deiner ganzen seele" ${ }^{u}$ ich dachte, wann bietet sich mir gelegenheit, dab ich es erfülle? und jetzt, wo sie sich mir darbietet, soll ich es nicht erfüllen?" - Beachte das wortspiel in 5 a. .

5 b) שער המורח (הר הפית) zum sog. frauenhof führende tor; vgl. über den 2. tempel die aus den quellen mit minutiöser sorgfalt gearbeitete darstellung von $\mathrm{Dalm}$ an, $\mathrm{Pa}$ lestinajahrbuch V, $29 \mathrm{ff}$.

5 c) vgl. dazu V, 3 f.; die 'b sind die leugner der auferstehung und der zukünftigen welt.

5 d) Ruih 2, 4, Jud. 6, 12, Prov. 23, 22, Ps. 119, 126; die beweiskraft!letzterer beiden stellen in diesem zusammenhang ist nicht recht einleuchtend.

\section{VerzeichniB der in Berakhoth erwähnten autoritäten.}

(vgl. Strack a. a. o. s. $84 \mathrm{ff}$. $-\mathbf{R}=\mathbf{R a b b a n}, \mathbf{r}=\mathbf{R a b b i}$. - Nur die mit * bezeichneten gehören dem 1. nachchr. Jhd. an, alle andern dem 2.)

r. Aqiba IV, 3 V, 2 VI, 8 VIII 3

r. Ben Azzaj IX, 4

r. Ben Zoma I, 5

*r. Chanina b. Dosa V, 5

r. Eleazar b. Azarja I, 5 IV, 7

r. Eliezer I, 1 IV, 4 V, 2 VII, 5

*R. Gamlie 1 I, 1 II, 5 f. IV, 3 VI, 8

r. Jose d. Galiläer VII, 3

r. Jose II, 3 r. Josua IV, 3 f.

r. Josua b. Korcha II, 2

r. Juda II, 1 f. II, 3 III, 4 u. 6 IV, 1 u. 7 VI, 1 u. 3 f. IX, 2

r. Ismael VII, 3

r. Meir II, 1

r. Nathan IX, 5

*r. Nechunja b.Haqqan a IV,2

*R. Simeon b. Gamliel II, 8

r. Tarphon I, 3 